\title{
Large-sized ichthyosaurs from the Lower Saurian niveau of the Vikinghøgda Formation (Early Triassic), Marmierfjellet, Spitsbergen
}

\author{
Victoria Sjøholt Engelschiøn 1,2, Lene Liebe Delsett ${ }^{2}$, Aubrey Jane Roberts ${ }^{3}$ \\ \& Jørn Harald Hurum²
}

\begin{abstract}
${ }^{1}$ Department of Geology and Mineral Resources Engineering, Norwegian University of Sciences and Technology, NO-7491 Trondheim, Norway. ${ }^{2}$ Natural History Museum, P.O. Box 1172 Blindern, 0318 Oslo, Norway.

${ }^{3}$ The Natural History Museum, Earth Sciences, Cromwell Road, London SW7 5BD, UK.
\end{abstract}

E-mail corresponding author (Victoria Sjøholt Engelschiøn):v.s.engelschion@nhm.uio.no

Humeri of Pessopteryx nisseri and vertebrae referred to Cymbospondylus sp. are described from the Lower Saurian niveau at Marmierfjellet, Spitsbergen. This is the most well-preserved Cymbospondylus material described from the Early Triassic so far, and the first description of new material of Pessopteryx nisseri since the species was established. The taxa are not represented by articulated or overlapping material. Herein, the most diagnostic material of both taxa is described and discussed, and the possibility that there is only one large-sized taxon present is suggested. Several specimens of Ichthyosauria indet. are also described. Comparisons are made to previously described specimens from the Lower Saurian niveau, including the disputed Merriamosaurus hulkei. The Boreal Ocean of Svalbard is of particular interest due to its position at the northern margin of Pangea, between the Early Triassic localities of today's British Colombia and Nevada, and South China. More than 2000 three-dimensional and disarticulated fragments show that large-sized ichthyosaurs had evolved and were numerous by the Early Triassic. This is the first time since the collections of Carl Wiman that the Lower Saurian niveau has been systematically sampled and placed in the modern stratigraphy.

Keywords: Ichthyopterygia, Svalbard, Triassic, Cymbospondylus, Pessopteryx, palaeontology, Boreal

Electronic Supplement A: Measurements

Received 23. November 2017 / Accepted 8. August 2018 / Published online 4. October 2018

\section{Introduction}

The Permian-Triassic boundary $(251.902 \mathrm{Ma} \pm$ 0.024, ICS v2017/02) saw the most devastating mass extinction event in Earth's history. In the aftermath, the Ichthyopterygia are thought to be one of the first amniote groups to become secondarily aquatic (Benton \& Twitchett, 2003), diversifying and filling the role as apex predators already in the late Early Triassic (Spathian) (Scheyer et al., 2014). Although their landliving diapsid ancestor is currently unknown, one of the basal traits shared by the Early Triassic ichthyopterygians is their small body size (Maisch \& Matzke, 2000; Motani et al., 2014). One of the richest Olenekian localities; the Nuanling Fm. in South China, has yielded three basal genera; two ichthyosauriforms; Cartorhynchus lenticarpus Motani et al., 2014 and Sclerocormus parviceps Jiang et al., 2016 and the ichthyopterygian Chaohusaurus geishanensis Young \& Dong, 1972, which are small forms retaining basal diapsid features like short snouts and elongated limb bones (Motani \& You, 1998; Motani et al., 2014; Jiang et al., 2016). Ichthyopterygians have been reported from Olenekian (Early Triassic) occurrences worldwide (Motani et al., 2014); scattered

Engelschiøn, V.S., Delsett, L.L., Roberts, A.J. \& Hurum, J.H. 2018: Large-sized ichthyosaurs from the Lower Saurian niveau of the Vikinghøgda Formation (Early Triassic), Marmierfjellet, Spitsbergen. Norwegian Journal of Geology 98, 239-265. https://dx.doi.org/10.17850/njg98-2-05. 
across Idaho and Nevada in the U.S.A (Massare \& Callaway, 1994; Kelley et al., 2016), the Sulphur Mt. Fm. in British Columbia, Canada (Nicholls \& Brinkman, 1995), the Osawa Fm. of Japan (Shikama et al., 1978), the Nanlinghu Fm. of China (Young \& Dong, 1972; Motani et al., 2014; Jiang et al., 2016) and the Vikinghøgda Fm. of Spitsbergen (Wiman, 1910, 1928), in addition to a probable Early Triassic ichthyopterygian from Thailand (Mazin et al., 1991) and possible ichthyosaurian remains from Western Australia (Kear, 2004; Kear et al., 2017).

The first ichthyopterygians to reach large sizes were Thalattoarchon saurophagis Fröbisch et al., 2013 at 8.6 $\mathrm{m}$ and Cymbospondylus spp. reaching sizes over 10 $m$ (Merriam, 1908) in the Anisian (Middle Triassic). Possible Cymbospondylus material has been reported from isolated remains in Early Triassic strata (Massare \& Callaway, 1994), but are otherwise mainly known from Middle Triassic deposits (Ji et al., 2015), with a disputed occurrence from the Late Triassic with Cymbospondylus asiaticus Li \& You, 2002 (see discussion in Fröbisch et al., 2006). Other large Triassic taxa are Besanosaurus leptorhynchus Dal Sasso \& Pinna, 1996, and Guizhouichthyosaurus tangae Cao \& Luo in Yin et al., 2000, found in the Middle Triassic, and Shastasaurus, Guanlingsaurus and Shonisaurus, in addition to other large, but incomplete specimens located in Late Triassic deposits (Fischer et al., 2014, Ji et al., 2015, Lomax et al., 2018).

\section{Large Early Triassic ichthyosaurs from Svalbard}

The Arctic Archipelago of Svalbard has long been known for its fossil richness, and ichthyopterygian material has been collected and described from the Triassic strata since the late $19^{\text {th }}$ century (Nordenskiöld, 1866; Hulke, 1873; Dames, 1895; Yakowlew, 1903). In 1910, the Swedish palaeontologist Carl Wiman described four bone-bearing niveaus in the Isfjorden area of central Spitsbergen (Wiman, 1910). Among them was the Lower Saurian niveau, from which he established the genus Pessopteryx and four species. The type species of the genus, Pessopteryx nisseri Wiman, 1910, was described from three-dimensionally preserved, isolated elements collected during an expedition to Tschermakfjellet in 1908 (Wiman, 1910). The humeri were described as "the same type" as the circular humerus described from the large Middle Triassic ichthyosaur Pessosaurus (= Ichthyosaurus Hulke, 1873) polaris Wiman, 1910 (Wiman, 1916, fig. 4), but a holotype for P. nisseri was not selected from the assemblage. Since then, $P$. nisseri has undergone numerous revisions, and is currently recognised as the generic name for the nonomphalosaurid remains from the Lower Saurian niveau as initially stated by Wiman (1916) (see discussion in Motani, 1999; Maisch \& Matzke, 2000; McGowan \& Motani, 2003; Maisch, 2010; with summary in Maxwell \& Kear, 2013).
The other species of Pessopteryx; Pessopteryx arctica Wiman, 1910, Pessopteryx pinguis Wiman, 1910 and Pessopteryx minor Wiman, 1910 were erected on isolated humeri (Wiman, 1910, pl. 10, figs. 1-3). Due to the undiagnostic and fragmentary humeri of $P$. arctica and $P$. pinguis, they are considered nomina dubia (Motani, 1999; followed by McGowan \& Motani, 2003; Maxwell \& Kear, 2013). The only complete holotype is the humerus of P. minor (Wiman, 1910, pl. 10, figs. 3-3A), which is distinctly different from the humeri of the type species $P$. nisseri (Motani, 1999). Merriam (1911) characterised the humerus of $P$. nisseri as "shastasaurian-shaped", to which Motani (1999) agreed and therefore reassigned $P$. minor to an ichthyopterygian incertae sedis, Isfjordosaurus minor Motani, 1999. The material collected by Wiman has formed the basis of our understanding of Early Triassic ichthyopterygians from Svalbard until today, and much of the material has been redescribed several times (Maxwell \& Kear, 2013).

Sporadic collections of Early Triassic ichthyopterygians from Svalbard were made by the Cambridge Spitsbergen Expeditions during geological fieldwork in 1948-1992 (= the Cambridge Arctic Shelf Programme (CASP) since 1975) and by the Muséum National d'Histoire Naturelle (MNHN), Paris, in 1964 (Lehman-MNHN expedition) and 1969 (Centre National de la Recherche Scientifique (CNRS)-MNHN expedition) (see review in Maxwell \& Kear, 2013). Svalbard remains one of the few localities worldwide with Early Triassic marine outcrops, and it is therefore of paramount importance for understanding the early evolution and dispersal of the first ichthyopterygians. Recent excavations in South China and Nevada have revealed new information regarding the origins of the Ichthyopterygia (see Benton et al., 2013; Motani et al., 2014; Jiang et al., 2016; Kelley et al., 2016) and consequently, Spitsbergen has become increasingly important for answering questions raised by other finds.

During the summers of 2014-2016, the Spitsbergen Mesozoic Research Group conducted three expeditions to Flowerdalen, Spitsbergen. These were the first excavations in the area to specifically target Early Triassic ichthyopterygians since the expeditions of De Geer, resulting in the 1910 publication of Wiman (see review in Maxwell \& Kear, 2013). The Lower Saurian niveau bone elements presented in this study are isolated and some are fragmentary, and caution is therefore crucial when interpreting the elements. Nonetheless, the different specimens have been tentatively assigned to anatomical positions where possible, for the ease of description and discussion. Undiagnostic ichthyosaurian material includes a potentially associated pelvic girdle, and jaws and limbs of large-sized ichthyosaurs, showing that large-bodied ichthyosaurs coexisted with the small ichthyopterygians. The assemblage also contains diagnostic remains of the large-sized ichthyosaurs Cymbospondylus sp. and Pessopteryx nisseri. Herein, 
abundant new material is described and the findings of large-sized ichthyosaur specimens of Olenekian age challenge long-standing notions about the evolution of body size among ichthyopterygians.

\section{Geological setting}

The Lower Saurian niveau forms a distinct horizon in the silty shale of the upper part of the Vendomdalen Member of the Vikinghøgda Formation (Mørk et al., 1999) and is of Late Olenekian, Spathian age (Weitschat \& Dagys, 1989; Dagys \& Weitschat, 1993; Hounslow et al., 2008; Weitschat, 2008; Hansen et al., 2018). The niveau is located between two, thin, yellow-weathering siltstone units approximately 2 metres below the base of the Botneheia Formation (see Hurum et al., 2018). The profile was measured at an exposure on the northern flank of Marmierfjellet.

The Lower Saurian niveau is approximately $95 \mathrm{~cm}$ thick (Fig. 1). The vertebrate remains typically fall within the size range of $<1 \mathrm{~cm}$ to $\sim 8 \mathrm{~cm}$ and are scattered throughout the niveau. The lower part of the niveau consists of an approximately 7-8 cm-thick limestone bed, which seems to have formed through compaction of diagenetic limestone nodules. The limestone is a darkgrey, yellow-weathering mudstone (Dunham, 1962). The limestone bed is overlying shale with several pyrite nodules. Above the limestone bed there is a $15 \mathrm{~cm}$-thick, thin-bedded, silty shale with lenticular bedding, thin calcite-cemented horizons and fragmentary fossils of bivalves ( 3-4 $\mathrm{mm}$ in diameter). Above the shale is a $6 \mathrm{~cm}$-thick, calcite-cemented, siltstone bed, also with bivalves and vertebrate remains. The bedding is approximately $3 \mathrm{~mm}$ thick and planar, and of a greyishbrown colour which weathers pale brown. Close to the top of the siltstone bed, there is a microsite with abundant fish scales and bone elements preserved. Approximately 8 $\mathrm{cm}$ above the siltstone bed, there is another thin layer of a similar microsite. The upper $60 \mathrm{~cm}$ of the niveau consists of a fine-grained silty claystone with occasional calcitecemented beds. Less concentrated ganoid elements are found throughout the interval, and so are also threedimensional vertebrate remains. The uppermost part of the silty shale is rich in $\sim 4 \mathrm{~cm}$-long, heavily weathered, reddish to orange pyrite nodules. The uppermost bed is a grey, silty limestone with yellow weathering, planar bedding and thin laminae of siltstone.

\section{Institutional abbreviations}

MNHN - the Muséum Nationale d'Histoire Naturelle, Paris, France (collection number: SVT); PIMUZ Paleontological Institute and Museum of the University of Zürich; PMO - Paleontological Museum Oslo, the University of Oslo, Oslo, Norway; PMU - Paleontological

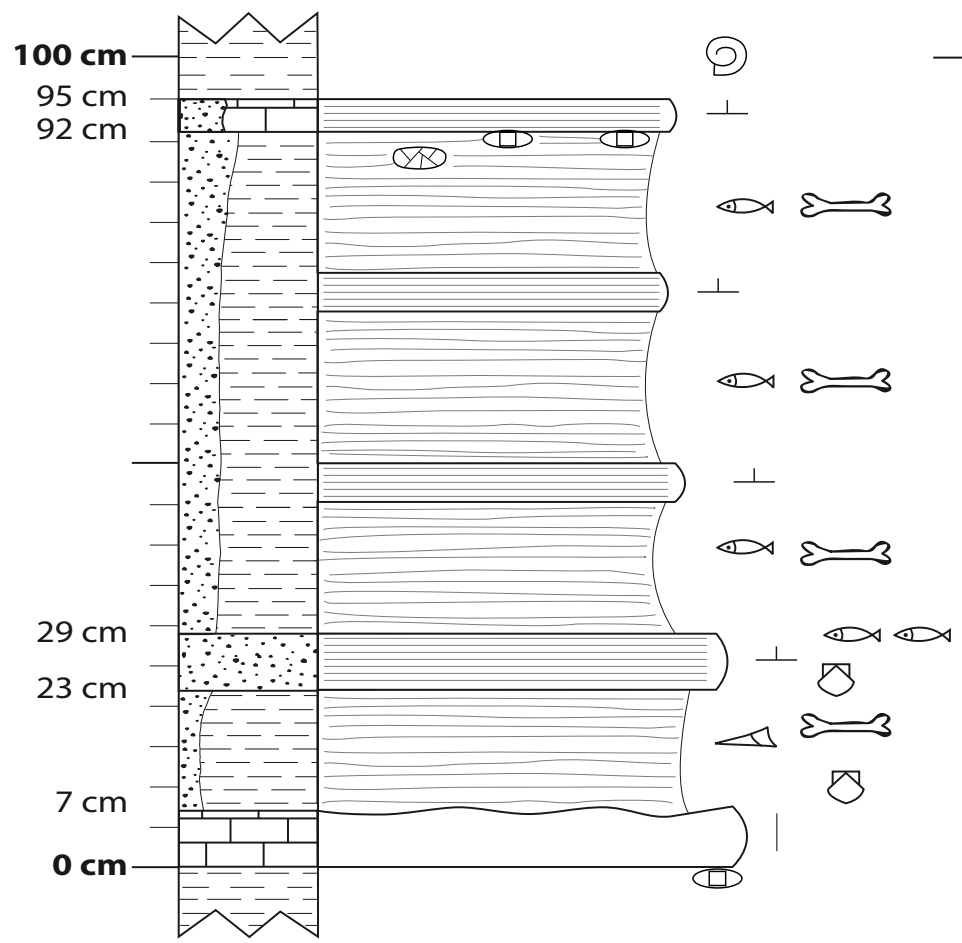

Legend

\begin{tabular}{|c|c|c|c|}
\hline$\because \because \because$ & Siltstone & (2) & Ammonoids \\
\hline & Grey shale & $\infty$ & Fish remains \\
\hline$-=-7$ & & $\Longleftrightarrow$ & Vertebrate remains \\
\hline \begin{tabular}{|l|l|l|}
1 & \\
1 & 1 \\
\end{tabular} & Limestone & 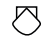 & Bivalves \\
\hline 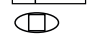 & Pyrite nodules & $\mid$ & No bioturbation \\
\hline 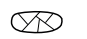 & Septarian nodules & $\perp$ & Calcite cementation \\
\hline$\infty$ & Lenticular laminati & ion & \\
\hline
\end{tabular}

$\triangle$ Lenticular lamination

Figure 1. Detailed log of the Lower Saurian niveau. See Hurum et al. (2018) for the complete Marmierfjellet section. Vertebrate remains and ganoid elements are scattered throughout the interval, with occasional findings of bivalves and ammonoids. The silty claystone has several thin, calcite-cemented horizons, and heavily weathered pyrite nodules are found both below the lowermost limestone bed and below the uppermost silty limestone. 
Collection, Museum of Evolution, Uppsala University, Sweden (replacing the old " $R$ " system, herein given in parentheses); UCMP - Museum of Paleontology, University of California at Berkeley.

\section{Materials and methods}

The Lower Saurian niveau is approximately one metre thick and could be followed laterally for approximately $3.5 \mathrm{~km}$. A total of 81 fossil collection sites along the niveau were registered and marked with a sample number, GPS coordinates and the date of collection. All necessary permits were obtained from the Governor of Svalbard for the excavations and fieldwork 20142016. Permits no. RiS 6725, 2013/1222-2; RiS 10227, 2015/00326-2; RiS 10539, 2015/00326-5.

The material described herein is presented together with a review of previously described ichthyosaurian material from the Lower Saurian niveau. Comparisons are made to other, large-sized ichthyosaurs from the Triassic period. McGowan (1994) reviewed the described species of Shastasaurus and considered several of them invalid. His interpretation is followed here (see discussion in McGowan, 1994); however, certain species names are used for ease of reference to older illustrations and figures.

The until now largest collection of Early Triassic ichthyosaurs from Svalbard has been the historical collections of the Palaeontological Collection, Museum of Evolution, Uppsala University, Sweden, housing a large amount of material from the Lower Saurian niveau. Upon inspection, the specimens were photographed, and identifiable elements were measured and described for comparison to the newly collected material from Svalbard.

Measurements were taken with a Vernier caliper, and recorded to the nearest $1 \mathrm{~mm}$. Some of the bone elements described in this study have been subject to intense weathering resulting in a lack of bone surface or broken margins, and only complete surfaces were measured. The mediolateral width of the vertebrae was measured at its maximum point, including the rib facets. In cases where the facets protruded to such a degree as to differ significantly from the edge of the centrum margin, both measurements were made. See Electronic Supplement A for selected measurements.

\section{Description of material}

\section{Systematic palaeontology}

Ichthyosauria Blainville, 1835.

Hueneosauria, Maisch \& Matzke, 2000.

Cymbospondylus Leidy, 1868.

Type species: Cymbospondylus piscosus Leidy, 1868.

Referred species: Cymbospondylus petrinus Leidy, 1868; Cymbospondylus buchseri Sander, 1989; Cymbospondylus nichollsi Fröbisch et al., 2006.

Locality and horizon: Early Triassic (Spathian) to Middle Triassic (Ladinian) of western Tethys, Boreal and eastern Pacific region.

\section{Cymbospondylus sp.}

Synonymy list:

1910 Pessopteryx nisseri n.g. et n. sp.; Wiman, pl. 9, figs. 33, 33A, 34 \& 34A.

2002 Merriamosaurus hulkei (Maisch \& Matzke, 2000); Maisch \& Matzke, fig. 2A, D-F.

2003 Merriamosaurus hulkei (Maisch \& Matzke, 2000); Maisch \& Matzke, fig. 2A-C.

Referred material: The new specimens atlas PMO 229.731, axis PMO 229.732, and dorsal vertebrae PMO 229.734, PMO 229.735, PMO 229.734, PMO 229.735, PMO 229.736, PMO 229.739, PMO 229.742, PMO 229.743, PMO 229.744, PMO 229.745, PMO 230.177, PMO 230.613, PMO 230.620, PMO 230.654, PMO 230.664, PMO 230.698, PMO 230.714, PMO 230.738, PMO 230.772, PMO 230.801, PMO 230.807, PMO 230.842, PMO 230.861, PMO 230.870, PMO 230.900, PMO 230.940, PMO 230.960, PMO 230.988, PMO 231.031, PMO 231.109, PMO 231.130, PMO 231.140, PMO 231.204, PMO 231.220, PMO 231.222, PMO 231.232, PMO 231.332 and PMO 231.342.

Remarks: Cymbospondylus sp. is identified on an atlas, an axis and 25 complete and 11 fragmented dorsal vertebrae from the Lower Saurian niveau. The dorsal vertebrae represent several individuals of different sizes and from various ontogenetic stages. The vertebrae are all fractured but uncompressed, and display varying degrees of weathering.

Atlas (PMO 229.731, Fig. 2A). The atlas is characteristic in having a convex anterior face, which has only been described in Cymbospondylus (Merriam, 1908; Sander, 2000). The outline in anterior view is nearly cardioid, and the mediolateral width is slightly greater than the dorsoventral height. One third of the lateral peripheral area of the anterior articular face is slightly concave, 

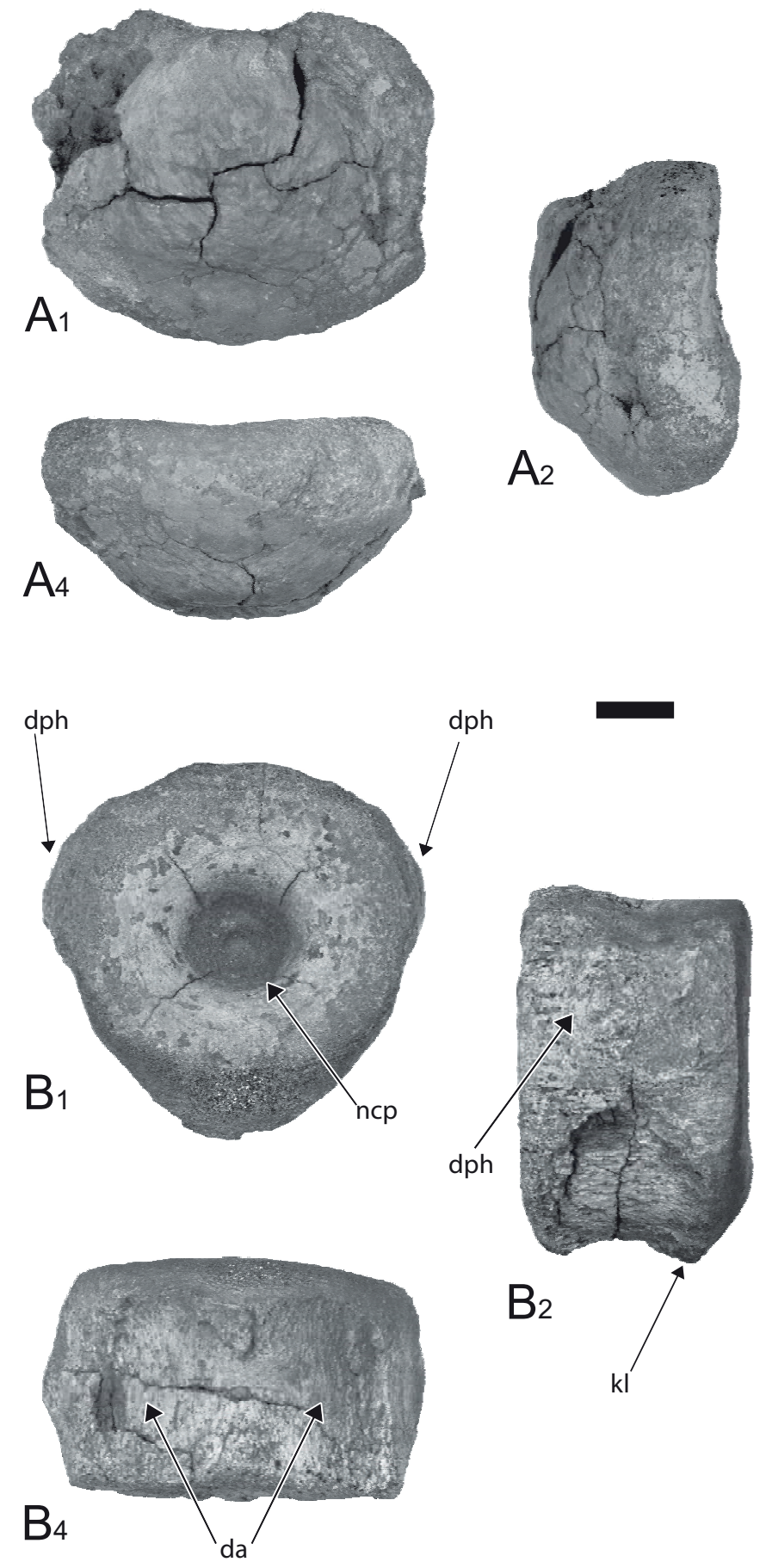

Figure 2. The atlas and axis of Cymbospondylus sp. (A) Atlas PMO 229.731 in A1: anterior view, A2: right lateral view, A3: posterior view, A4: ventral view, A5: dorsal view. (B) Axis PMO 229.732 in B1: anterior view, B2: right lateral view, B3: posterior view, B4: ventral view, B5: dorsal view.

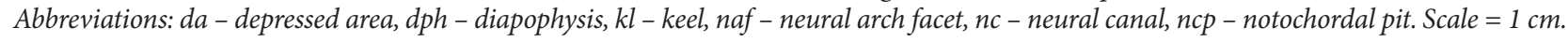

whereas the centremost area of the centrum is strongly convex and forms an anterior protrusion. A small notochordal pit is placed centrally on this elevated area. In lateral view, there is a dorsoventral depression close to the posterior margin. This structure may be an erosional artefact or a remnant of the separation between the diapophysis and the parapophysis, though there are no recognisable facets. The neural canal forms a mediolaterally wide groove, which decreases anteriorly
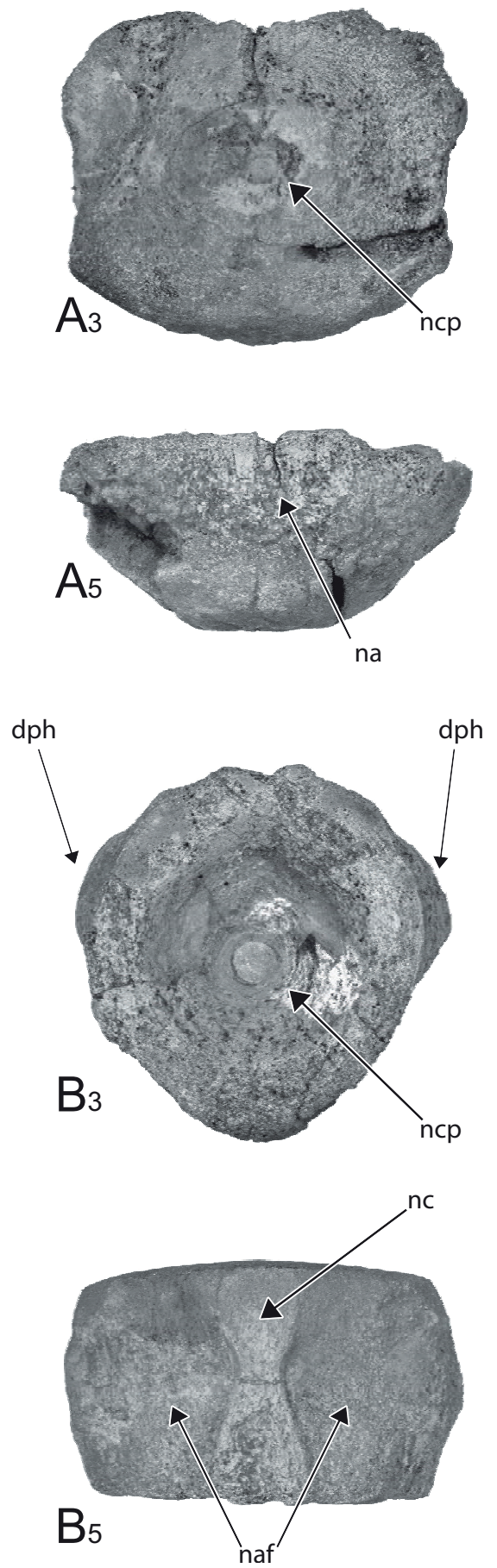

until it terminates at the elevated central portion of the anterior face of the vertebra.

Axis (PMO 229.732, Fig. 2B). The axis is referred to Cymbospondylus sp. based on the presence of a ventral keel in anterior view, anterodorsally expanded diapophyses and a concave rim on the anterior face of the centrum (Merriam, 1908). The outline in anterior view is suboval. The greatest mediolateral width is across 
the diapophyses on the dorsal half of the centrum. The dorsoventral height is only slightly less than the mediolateral width. The peripheral lateral margin on the anterior face is convex, leading to a deep and strongly concave notochordal pit. The peripheral area of the posterior face is similarly convex, although less pronounced. The medial three-fourths of the posterior face slopes concavely towards the notochordal pit. The diapophyses are heavily weathered, but they appear to have been in direct contact with the neural arch facets dorsally. In lateral view, they are positioned slightly more towards the anterior face of the vertebra. The parapophyses are absent, similar to most specimens of Cymbospondylus petrinus (Merriam, 1908, pl. 8, fig. 6). The neural canal is constricted mediolaterally along the anteroposterior midline. In ventral view, the axis has a broad but shallow depression over the lateral surface, extending dorsally to the diapophyses, a feature which is identical to the condition seen in the axis of C. petrinus (Merriam, 1908, pl. 8, fig. 1A).

The atlas PMO 227.731 and axis PMO 229.732 were collected from the same geographical location and could potentially have been articulated. Similar to what has been described for Cymbospondylus petrinus, this atlas and axis have near-equal dorsoventral height and mediolateral width, and the anteroposterior length of the atlas is three-fourths of that of the axis (Merriam, 1908, fig. 38 \& pl. 8, figs. $1-3 \& 5-6$ ).

Dorsal vertebrae (PMO 229.734, PMO 229.735, PMO 230.177, Fig. 3). The vertebral centra are assigned to Cymbospondylus sp. based on the characteristic truncation of the diapophyses on the anterior margin of the centrum (Merriam, 1908; Sander, 1989, 1992; Fröbisch et al., 2006).

The relative position of the dorsal vertebrae is assigned based on the posteriorly reduced contact between the diapophysis and the neural arch facet, and the outline of the centra in anterior view. The outline changes posteriorly and the relative position can be given by comparison to other specimens with respect to the dorsoventral height / anteroposterior length $(\mathrm{H} / \mathrm{L})$ and dorsoventral height / mediolateral width $(\mathrm{H} / \mathrm{W})$ ratios (Sander, 1989, 1992).

In lateral view, the diapophyses are anteriorly slanting and ventrally elongated with the ventralmost part touching the anterior margin. In anterior dorsal vertebra PMO 229.734, the diapophyses are directly connected to the neural arch facet; approximately two-thirds of the dorsoventral length of the diapophyses is positioned with equal distance to the anterior and posterior margin of the centrum, and the ventral one-third bends anteriorly until the entire facet is truncated by the anterior margin of the centrum. In mid-dorsal vertebra PMO 229.735, the connection between the neural arch facet and the diapophysis is reduced to a distinct ridge that extends ventrally from the facets to the dorsalmost margin of the diapophyses, midway on the dorsal part of the centrum in lateral view. This ridge is identical to that described from the posterior dorsals of Cymbospondylus petrinus by Merriam (1908, fig. 130). Ventral to the ridge, approximately half the dorsoventral length of the diapophysis is truncated by the anterior margin of the centrum. In midposterior dorsal vertebra PMO 230.177, the diapophyses are placed centrally on the dorsoventral midline of the centrum. The diapophyses are almost completely separated from the facets for the neural arch, and a remnant of the connecting ridge can be seen in right lateral view as a slightly dorsoventrally elevated line.

The dorsal vertebra, referred to an Early Triassic Cympospondylus sp. by Massare \& Callaway (1994, fig. $2 \mathrm{D}, \mathrm{E})$, display the same characteristic diapophyses as the material described herein. The dorsal vertebra PMU 24630 (Wiman, 1910, pl. 9, fig. 33-33A, the latter which is figured upside-down) and PMU 24633 (Wiman, 1910, pl. 9, fig. 34), both show the anteriorly truncated diapophyses diagnostic of Cymbospondylus. Four dorsal vertebrae that were assigned to the questionable Merriamosaurus hulkei by Maisch \& Matzke (2002) together with another anterior dorsal also referred to M. hulkei (Maisch \& Matzke, 2003, fig. 2A), are clearly diagnostic to Cymbospondylus based on their anteriorly truncated diapophyses. Maisch and Matzke (2002, fig. 2A) also depicted an M. hulkei atlas with the convex anterior face considered diagnostic for Cymbospondylus (Merriam, 1908; Sander, 2000).

In anterior view, anterior dorsal PMO 229.734 is subcircular, slightly mediolaterally wider than dorsoventrally high. It has a H/L ratio (1.79) similar to that of the $14^{\text {th }}$ centrum of Cymbospondylus buchseri (1.74) (Sander 1989), and a H/W ratio (0.91) identical to that described for anterior dorsal PIMUZ A/III 554 (0.90) from Botneheia, Spitsbergen, referred to Cymbospondylus sp. (Sander, 1992). The outline of mid-dorsal PMO 229.735 and midposterior dorsal PMO 230.177 is teardrop-shaped, with the greatest mediolateral width located just ventral to the dorsoventral midline. The dorsoventral height and the mediolateral width are approximately twice the size of the anteroposterior length. PMO 230.177 has a H/L ratio (2.17) similar to the $48^{\text {th }}$ centrum of C. buchseri (2.18) (Sander, 1989) and to PMO 162.003 (= "PIMUZ A/III 496", see Lindemann, 1998), referred to Cymbospondylus sp. and interpreted to be the $42^{\text {th }}$ centrum (2.18) (Sander, 1992).

In anterior or posterior view, the ventral edge is rounded. Both articular faces of the dorsals are concave with marginal flattening on the outermost lateral peripheral surfaces. The marginal flattening is less pronounced in the anterior dorsal. However, in the mid and midposterior dorsals, the lateral peripheral area of both articular faces is flat for about two-thirds medially towards the centre, where it slants abruptly, forming a pronounced 
deepening with a notochordal perforation, as has been well described for Cymbospondylus (Merriam, 1908; Sander, 1992).
In dorsal view, the dorsal vertebrae have distinct neural arch facets separated by a medially constricted neural canal along the anteroposterior midline.
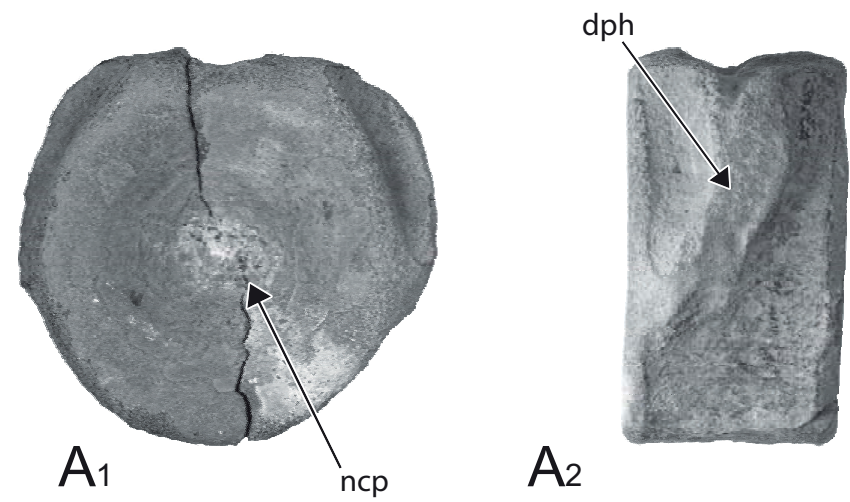

$\mathrm{A}_{3}$
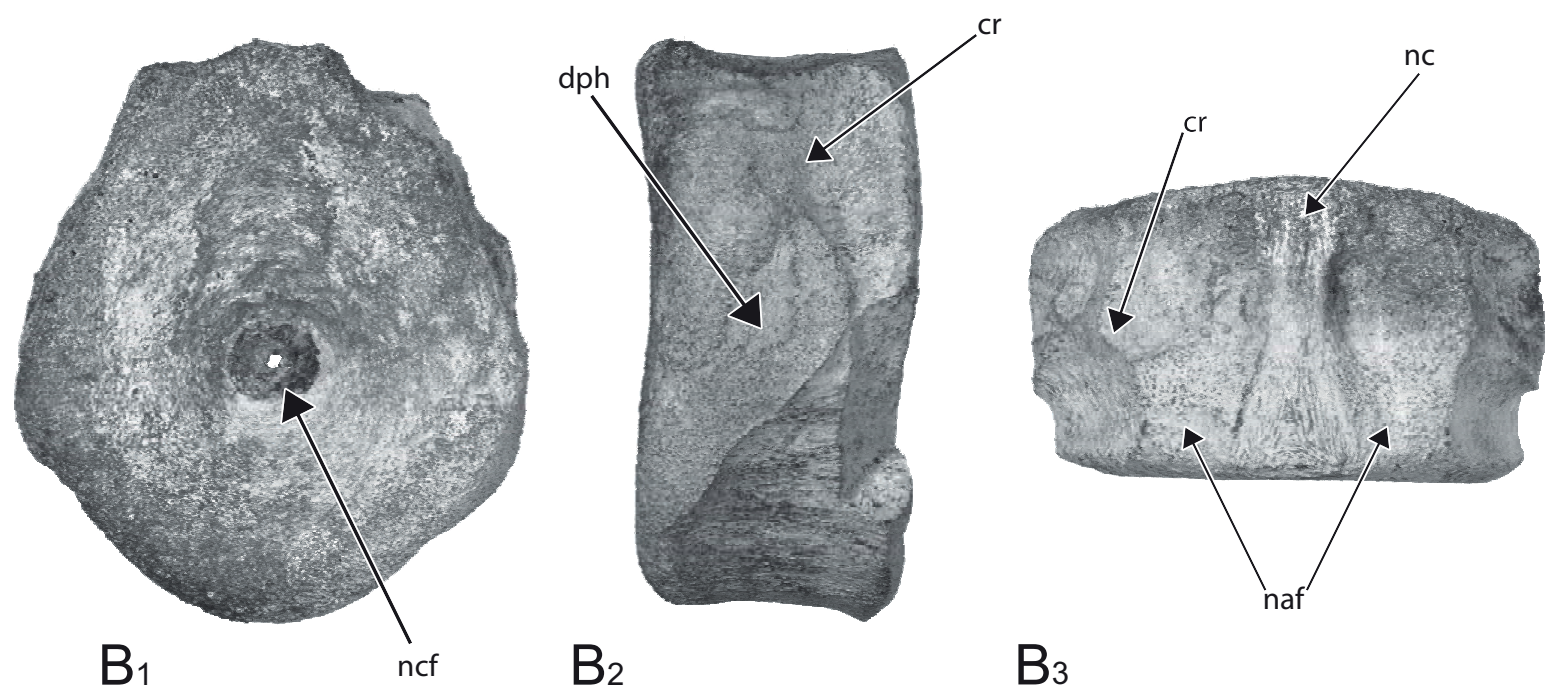

$\mathrm{B}_{2}$

$\mathrm{B}_{3}$
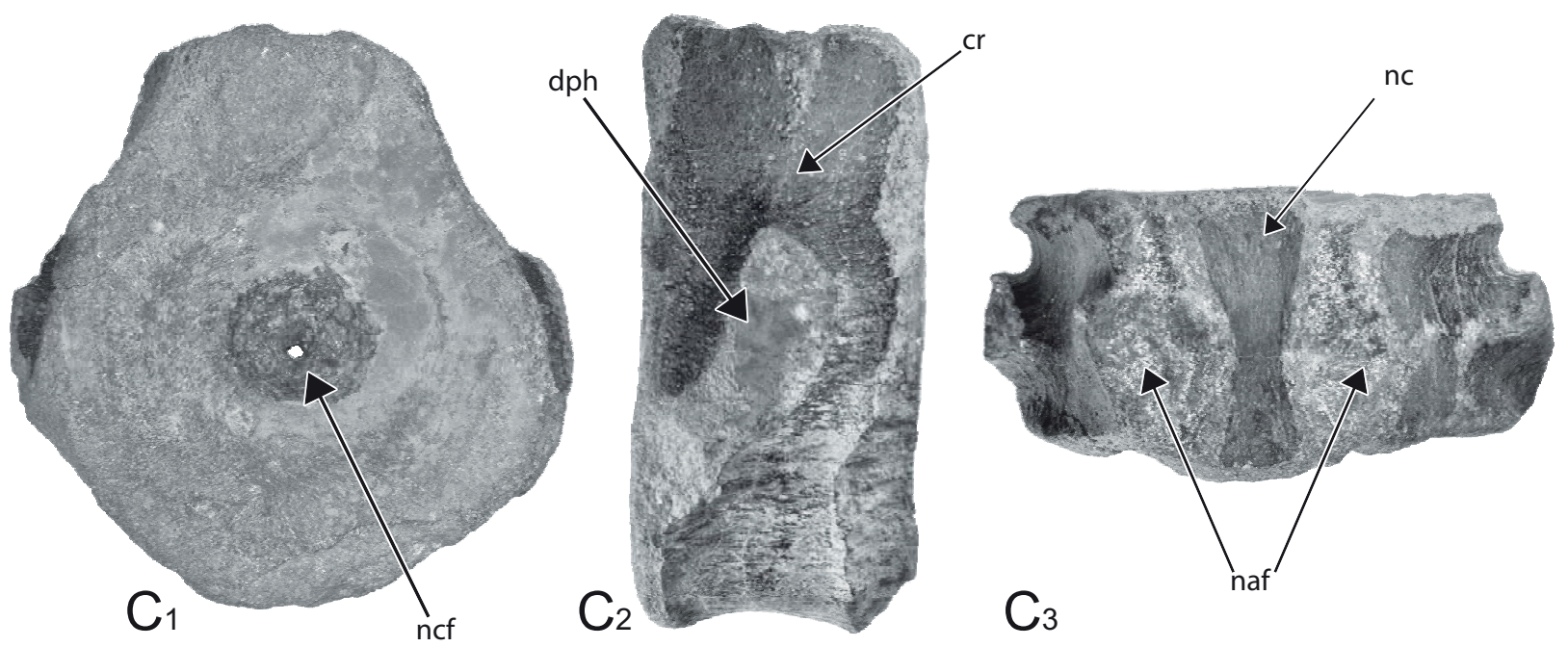

Figure 3. Dorsal vertebrae of Cymbospondylus sp. (A) Anterior dorsal vertebra PMO 229.734 in A1: anterior view, A2: left lateral view, A3: dorsal view. (B) Mid-dorsal vertebra PMO 229.735 in B1: anterior view, B2: left lateral view, B3: dorsal view. (C) Mid-dorsal vertebra PMO 230.177, where diapophyses are connected to the neural arch by a crest in C1: anterior view, C2: right lateral view (mirrored), C3: dorsal view. Abbreviations: $c r$ - crest, dph - diapophysis, naf - neural arch facet, $n c$ - neural canal, ncf - notochordal foramen, ncp - notochordal pit. Scale $=1 \mathrm{~cm}$. 


\section{Systematic palaeontology}

Ichthyosauria Blainville, 1835.

Hueneosauria, Maisch \& Matzke, 2000.

Pessopteryx Wiman, 1910.

Pessopteryx nisseri Wiman, 1910.

Type species: Pessopteryx nisseri Wiman, 1910.

Referred species: Type species only.

Locality and horizon: Early Triassic (Spathian) Vendomdalen Mb. of Vikinghøgda Fm., Spitsbergen.

Type material: PMU 24591 (R1075) (lectotype), PMU 4592/b (R300) (paralectotype), PMU 2492/a (R301) (paralectotype).

Synonymy list:

1910 Pessopteryx nisseri n.g. et $\mathrm{n}$. sp.; Wiman, pl. 8, figs. 1-4.

non 1910 Pessopteryx nisseri n.g. et n. sp.; Wiman, pl. 9, figs. 23-30, 33, 33A, $34 \& 34 \mathrm{~A}$.

1911 cf., Omphalosaurus; Merriam, pp. 324-326 (partim).

1916 Pessopteryx nisseri; Wiman (partim).

1983 Omphalosaurus nisseri (Wiman , 1910); Mazin (partim, SVT 218, SVT 219).

?1984 Pessosaurus (= ?Omphalosaurus) polaris; Mazin, pl. II, fig. D (SVT 293).

1999 Pessopteryx nisseri Wiman, 1910; Motani (partim).

non 2000 Omphalosaurus nisseri; Motani, p. 297.

2000 Rotundopteryx hulkei gen. et sp. nov.; Maisch \& Matzke, pp. 65-67 (4 humeri).

2002 Merriamosaurus hulkei (Merriamosaurus n.g. pro Rotundopteryx); Maisch \& Matzke, p. 61 (partim).

2003 Merriamosaurus hulkei Maisch \& Matzke, Fig. 5 (partim, SVT 219, ?SVT 293, ?SVT 292).

2003 Pessopteryx nisseri Wiman, 1910; McGowan \& Motani, pp. 135-136 (partim).

2010 Pessopteryx nisseri Wiman, 1910; Maisch, pp. 162-163.

Referred material: The near-complete to complete humeri PMO 229.778, PMO 229.779, PMO 229.780, PMO 229.781 and PMO 229.782, and the fragmented PMO 230.159.

Historical review: The type species, Pessopteryx nisseri, was erected based on the majority of the material that was pictured and interpreted to be ichthyosaurian from the Lower Saurian niveau by Wiman (1910). The material consists of four humeri (pl. 8, figs. 1-4), four femora (pl. 9, figs. 1-4), a radius (pl. 8, fig. 6), a fibula (pl. 8, fig. 9), a tibia (pl. 8, fig. 10), a ?scapula (pl. 8, fig. 16), a ?coracoid (pl. 9, fig. 5), several vertebrae (pl. 9, figs. 31-37), podial elements (pl. 8, figs. 5-10 \& Figs. 20-33) and dentigerous fragments (pl. 9, figs. 23-30).

Motani (1999) placed Pessopteryx as a genus incertae sedis within the Shastasauria, which was defined as having a humerus of near quadrangular shape, independent of the presence of an anterior flange. Due to the controversy regarding the relationship between Omphalosaurus and Pessopteryx, Maisch \& Matzke (2000) argued that the dental remains should be referred to Pessopteryx nisseri and that a new genus and species, Merriamosaurus (= Rotundopteryx) hulkei, should be erected for the postcranial material. One of the original humeri of P. nisseri (Wiman, 1910, pl.8, fig. 1) was chosen to be the holotype (Maisch \& Matzke, 2000). Maisch \& Matzke (2002) described the first supposedly associated material of $M$. hulkei. However, the specimen had been collected by the MNHN from several localities. McGowan \& Motani (2003) asserted that Wiman (1910) had referred to the ichthyosaurian postcranial material when establishing P. nisseri. They therefore considered Rotundopteryx to be a junior synonym of Pessopteryx, although the genus was invalid due to the undiagnostic material of the type species. McGowan \& Motani (2003) also mentioned the possibility that $P$. nisseri could be synonymous to Besanosaurus leptorhyncus or share a generic identity. Maisch (2010) eventually agreed that it would be correct to designate the ichthyosaurian postcranial material to P. nisseri. As Wiman (1910) did not elect a holotype when erecting P. nisseri as the type species of Pessopteryx, Maisch (2010) chose the humerus PMU 24591 (R1075) to be the lectotype (Wiman, 1910, pl: 8, fig. 2) and the two smaller humeri PMU 24592/b (R300) and PMU 2492/a (R301) as the paralectotypes (Wiman, 1910, pl. 8, fig. 3-4). M. hulkei thereby became a junior synonym of $P$. nisseri (see International Commission of Zoological Nomenclature, Article 23: "Principle of Priority"). However, by choosing another lectotype for $P$. nisseri than the holotype of $M$. hulkei, this led to the two taxa being subjective synonyms. Today, $P$. nisseri is considered diagnostic based on its forelimb traits (Maxwell \& Kear, 2013).

Remarks: Wiman (1910) described the teeth of Pessopteryx nisseri as uniformly smooth, with hemispherical tooth-crowns arranged in numerous rows. Merriam (1911) recognised the resemblance that these dental elements (pl. 9, figs. 23-30) shared with dental elements of the Middle Triassic type specimen Omphalosaurus nevadanus Merriam, 1906, from Nevada. Merriam (1911) therefore suggested that Pessopteryx and Omphalosaurus could have a common generic identity. This was also supported by undescribed "Shastasaurustype" limb elements found close to $O$. nevadanus resembling those of $P$. nisseri. Wiman (1916) agreed with the referral of the hemispherical teeth to Omphalosaurus. However, due to the fragmented nature of both specimens and the resemblance between the humeri of $P$. nisseri 

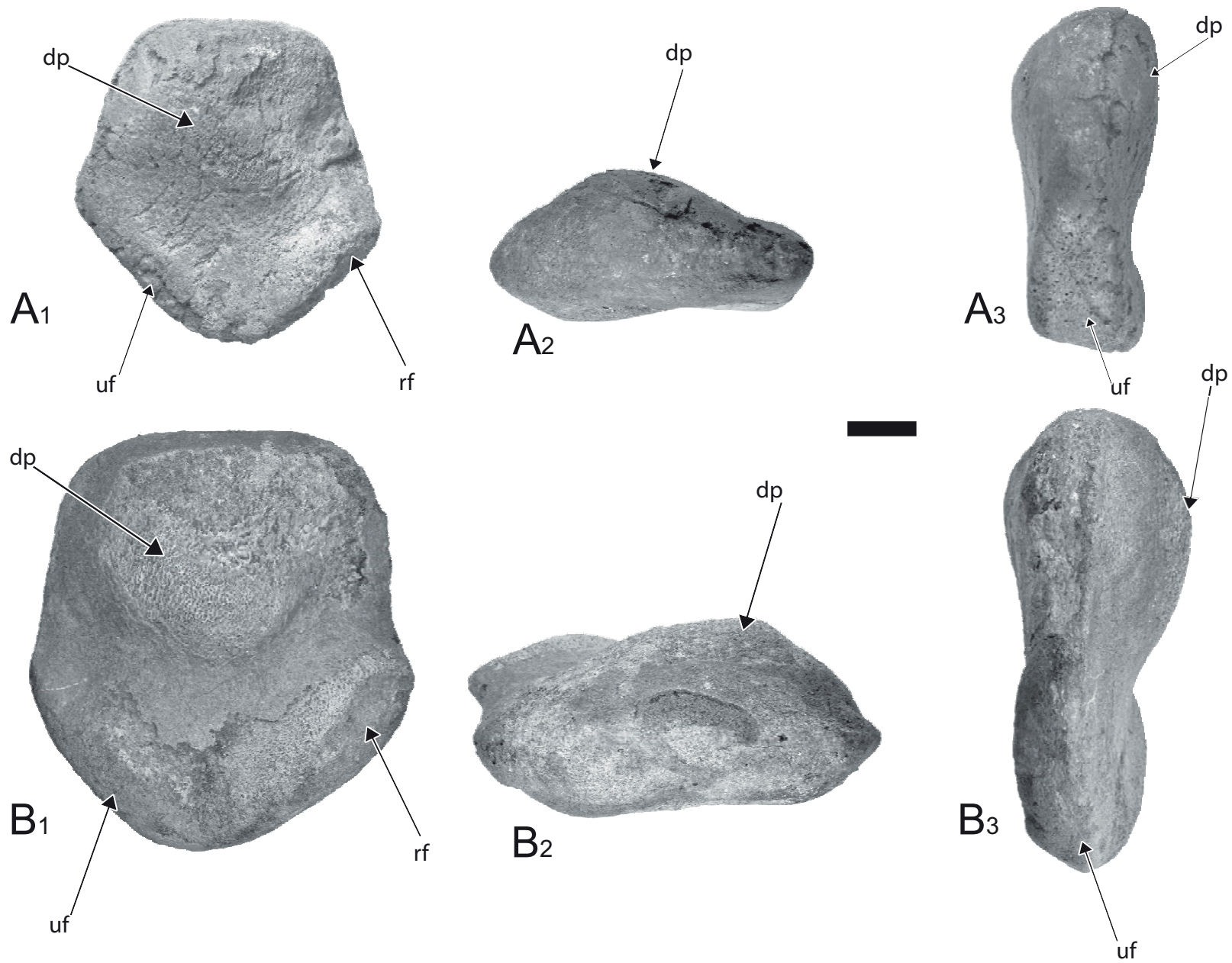

$\mathrm{B}_{2}$
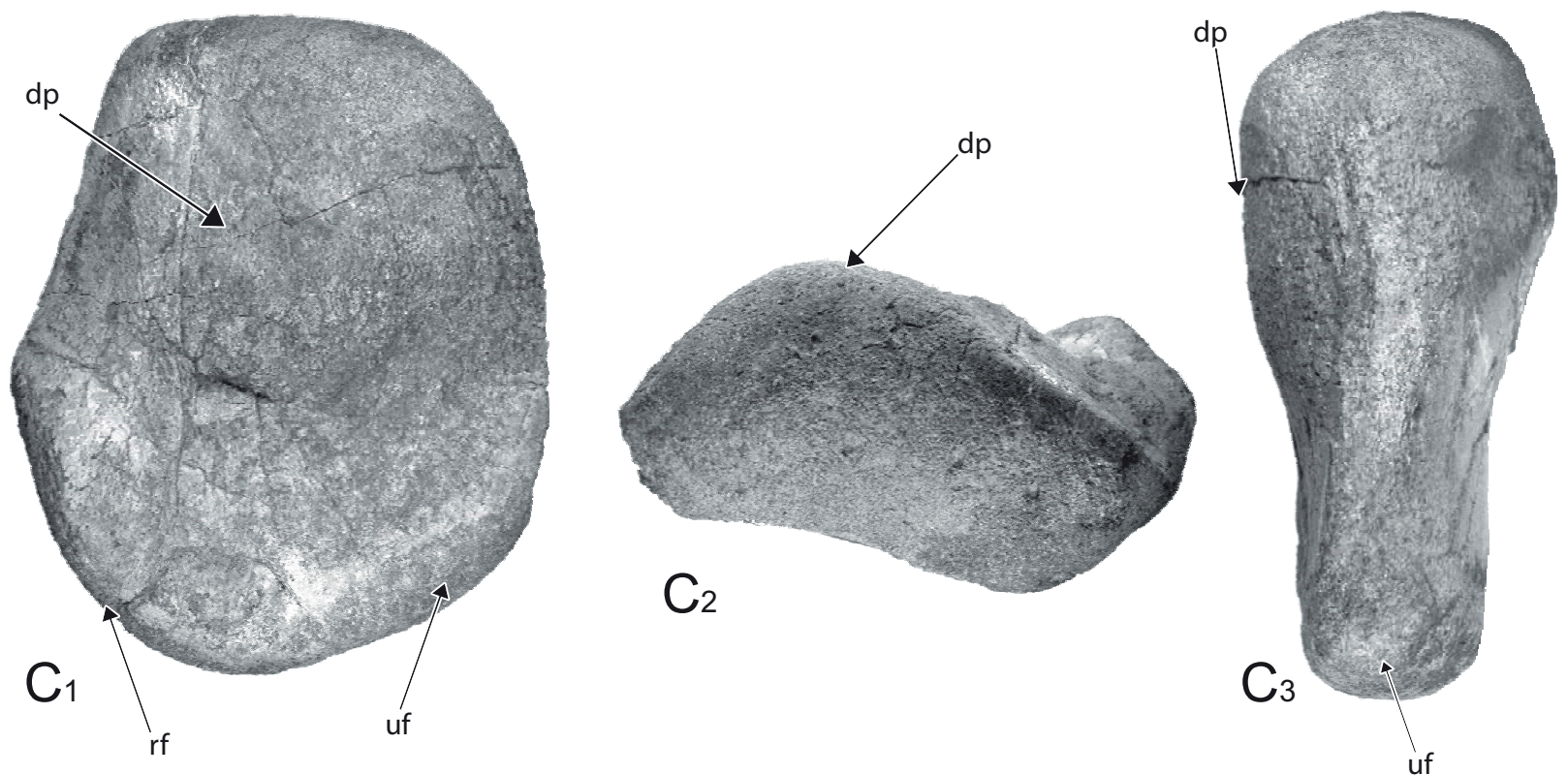

Figure 4. Humeri of Pessopteryx nisseri. (A) Right humerus PMO 229.778 in A1: dorsal view, A2: proximal view, A3: posterior view. (B) Right humerus PMO 229.779 in B1: dorsal view, B2: proximal view, B3: posterior view. (C) Left humerus PMO 229.780 in C1: dorsal view, C2: proximal view, C3: posterior view. Abbreviations: dp - dorsal process, $r f$-radial facet, uf - ulnar facet. Scale $=1 \mathrm{~cm}$.

and Pessosaurus polaris, Wiman (1916) concluded that P. nisseri was more likely an ichthyopterygian than an omphalosaurid and refrained from making further comparisons. Later, Mazin (1983) went further than
Merriam and referred $P$. nisseri to Omphalosaurus nisseri, based on the discovery of Omphalosaurus dental elements in the MNHN collections. Pessopteryx was thereby made a junior synonym of Omphalosaurus 
(Mazin, 1983). Motani (1999) later restored Pessopteryx as the generic name for the ichthyopterygian remains described by Wiman (1910). A designation was therefore needed for the omphalosaurid remains (see details in Ekeheien et al., 2018).
Humeri (See Systematic Palaeontology above for the list of specimens, Figs. 4 \& 5). The humeri described herein are referred to Pessopteryx nisseri on the basis of these traits; no anterior notch, the humeri are near-isometric, no constricted humeral shaft, the anteroposterior length of the proximal surface is about three-fourths

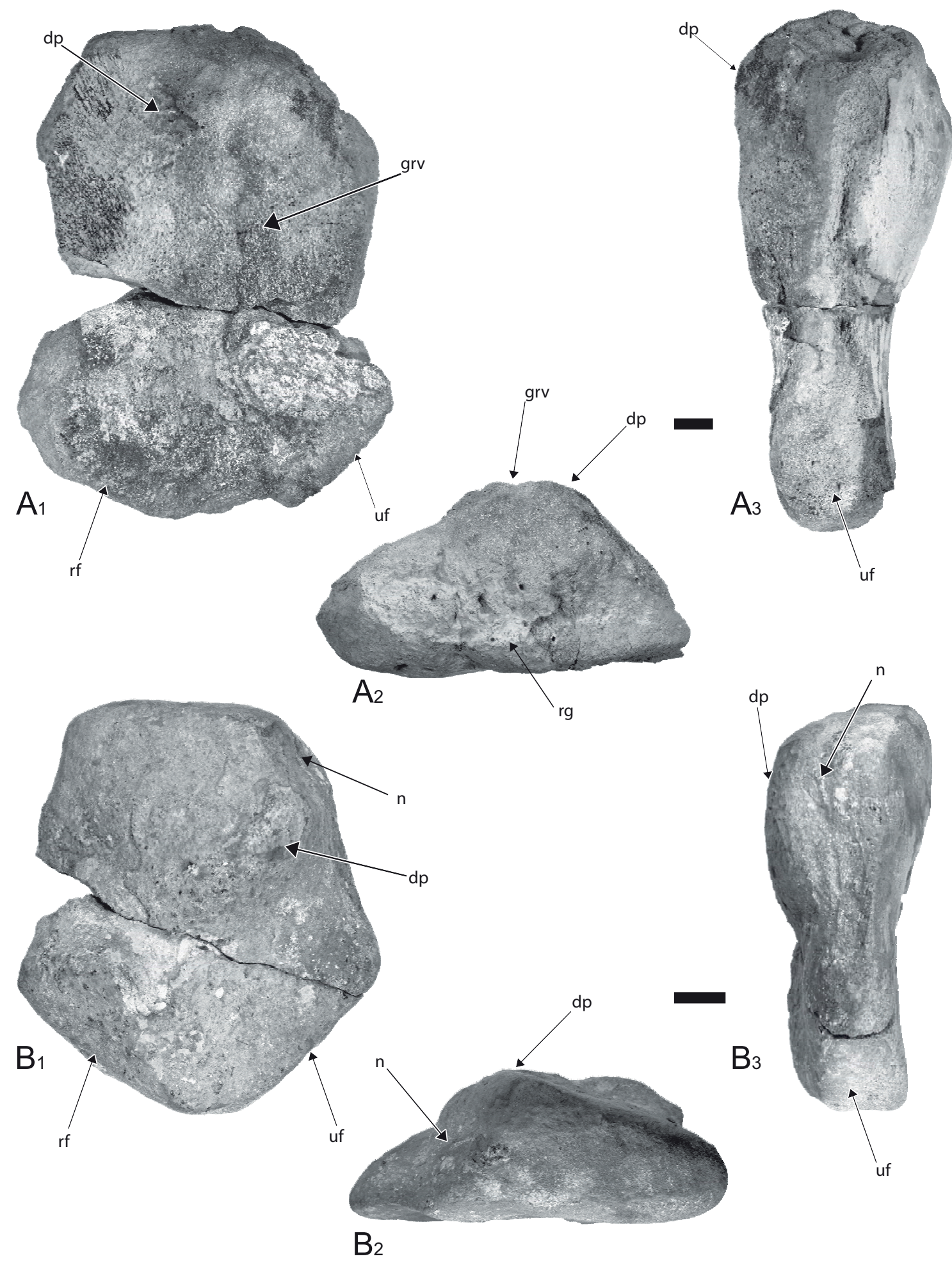

Figure 5. Humeri of Pessopteryx nisseri. (A) Left humerus PMO 229.782 in A1: dorsal view, A2: proximal view, A3: posterior view. (B) Left humerus PMO 229.781 in B1: dorsal view, B2: proximal view, B3: posterior view. Abbreviations: $d p-d o r s a l$ process, grv - groove, $n-$ notch, $r f$ - radial facet, $u f-u l n a r$ facet. Scale $=1 \mathrm{~cm}$. 
the anteroposterior distal length, the dorsal process slants anteriorly, the proximal articular surface is flat, the radial facet is slightly anteroposteriorly longer than the ulnar facet and dorsally expanded. In posterior view, the proximal half of the element is around twice as thick dorsoventrally as the distal half. The humeri are uncompressed and mostly complete, except PMO 230.159 where only the distal part of the element is preserved (not figured). Weathering has removed much of the cortical bone surface in all specimens. Based on the anteriorly slanting dorsal process and the dorsally expanded radial facet, it is possible to distinguish between right (Fig. 4A, B) and left (Figs. 4C \& 5) humeri with relative confidence.

The humeri are significantly smaller and more pentagonal in shape than the material collected by Wiman (1910). In dorsal view, the anterior margin is similarly concave, but the posterior margin forms a straight line, unlike the convex edge of the larger para- and lectotypes. Unfortunately, it is not possible to determine the outline of the larger PMO 229.782. The smaller humeri display less developed rugose surfaces on the articular facets and proximal articulation surfaces and could represent earlier ontogenetic stages. PMO 229.780 has small pits (diameter $\sim 1-2 \mathrm{~mm}$ ) on the proximal articulation surfaces that could be interpreted as endochondral ossification, but these are significantly less developed than the 3-4 mm-deep rugosities clearly visible on the larger specimens PMO 229.782 and PMO 230.159 , and in the lectotype and paralectotypes. The flat proximal articulation surface seen in the four small humeri is suggested to be a juvenile trait (Johnson, 1977). However, the proximal articulation surface in the large specimen PMO 229.782 is weathered, but also appears to be flat. A flat proximal articular surface could therefore be a feature that is independent of ontogeny in Pessopteryx nisseri.

The dorsal process is dorsoventrally low and anteroposteriorly wide, slanting anteriorly as in the majority of ichthyosaurs (McGowan \& Motani, 2003). The dorsal process is best preserved in PMO 229.781, where it forms a distinctly protruding ridge that terminates pointing towards the dorsally extended radial facet. It originates near the proximoposterior surface, and curves towards the anterior margin at approximately 45 degrees. The dorsal process spans about two-thirds of the humerus proximodistally, and in the small specimens it ends at an angle about one-third of the proximodistal length from the radial facet. PMO 229.782 displays a groove which could be an artefact of preservation. It runs proximodistally on the dorsal process and terminates immediately distal to the midshaft breakage point of the element. PMO 229.781 has a small notch posterior to the most proximal part of the dorsal ridge, immediately distal to the posterior end of the proximal articular surface. It is currently not possible to determine whether this notch is an erosional artefact, as the smaller humeri (Fig. 4) have less distinct features and the larger PMO 229.782 (Fig. 5A) is lacking this part of the element. There are two distal articular facets. The radial facet is dorsally expanded, and its termination creates a anterolaterally positioned flange on the distal end of the dorsal surface. The radial facet is slightly anteroposteriorly longer than the ulnar facet and approximately one-third dorsoventrally thicker (Figs. 4A \& 5B).

\section{Ichthyosauria Blainville, 1835}

Ichthyosauria indet.

\section{Cervical vertebra (PMO 229.733, Fig. 6A).}

The cervical is complete and uncompressed but lacks surface bone on the lateroventral margin of the posterior articular face. It is identified as a cervical vertebra based on the retention of parapophyses, which are lost in the posterior vertebra of Shastasaurus (Merriam, 1908) and from the seventh cervical in Cymbospondylus buchseri and Cymbospondylus petrinus (Merriam, 1908; Sander, 1989). This is also described for the more derived Californosaurus perrini (Kuhn, 1934) (= Shastasaurus perrini Merriam, 1902 and Delphinosaurus perrini Merriam, 1905).

The outline in anterior view is almost hexagonal. The mediolateral width of the centrum is one-sixth greater than the dorsoventral height. A slight ventral keel is present on the anterior margin in lateral view, however, as the specimen is weathered it is not possible to establish the original extent of the keel, which gradually ceases towards the posterior margin. The lateral half of the margin on the anterior face of the centra is flat. The centrum is deeply amphicoelous in the medial half of both faces of the centra, and the notochordal pit is deep. The cervical vertebra is mediolaterally wider than dorsoventrally tall and has a ventral keel, similar to the cervicals of "Shastasaurus osmonti" Merriam, 1902 (Merriam, 1902, pl. 8, fig. 2) and Besanosaurus leptorhynchus (Dal Sasso \& Pinna, 1996, fig. 13A). The cervicals of Cymbospondylus petrinus are distinguishable from PMO 229.733 by being dorsoventrally taller than mediolaterally wide.

The diapophyses are placed directly ventral to the neural arch facets. They are anteroposteriorly elongated, cover the entire anteroposterior length of the vertebra and are dorsoventrally taller posteriorly. There is a small dorsoventral constriction at the anterior margin of the centrum. The parapophyses are round and placed directly ventral to the dorsoventral midline, close to the anterior margin of the centrum. The neural canal is hour-glass shaped with a medial constriction on the anteroposterior midline.

PMO 229.733 differs from Besanosaurus leptorhynchus by having diapophyses placed ventrally to the neural 


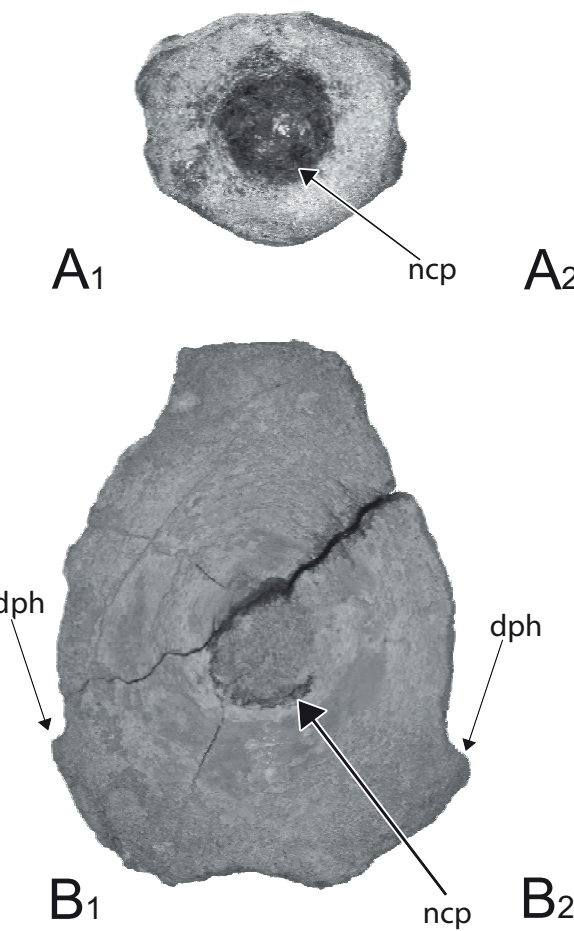

$\mathrm{A}_{2}$

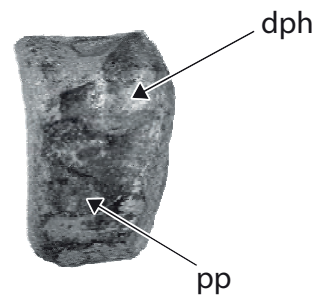

$\mathrm{B}_{2}$
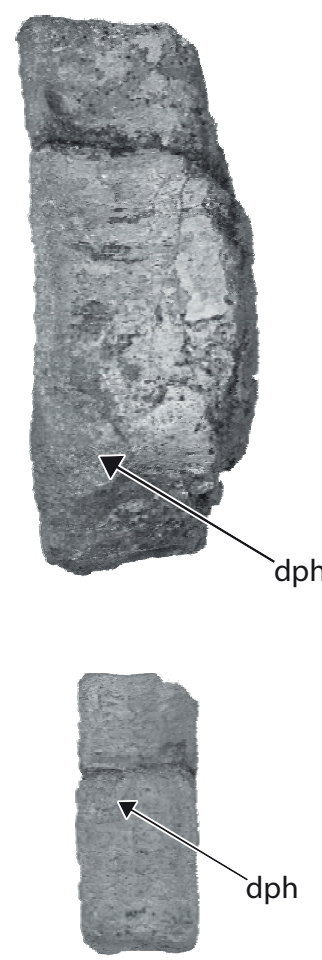

$\mathrm{C}_{1}$

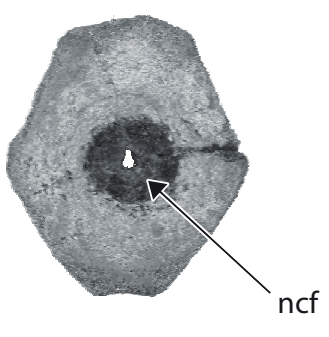

$\mathrm{D}_{1}$

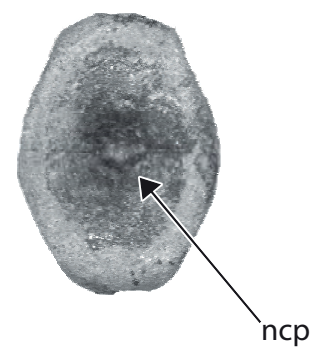

$\mathrm{C}_{2}$

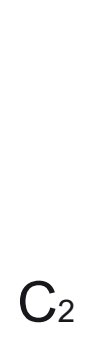

$\mathrm{D}_{2}$

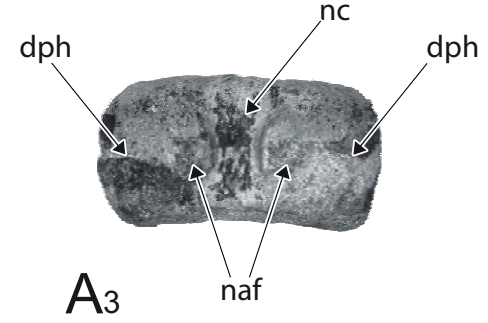

$\mathrm{A}_{3}$

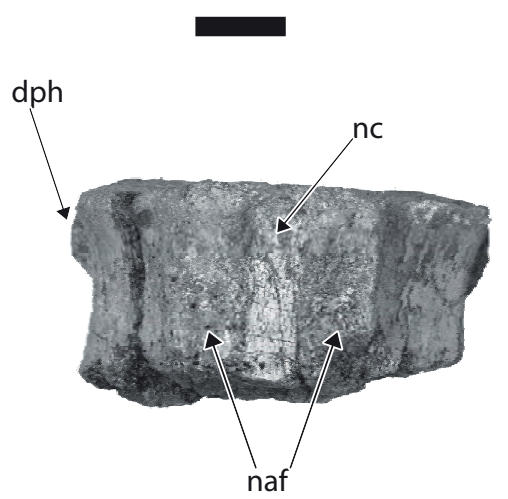

$\mathrm{B}_{3}$

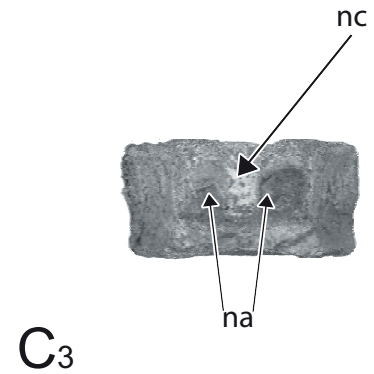

$\mathrm{D}_{3}$

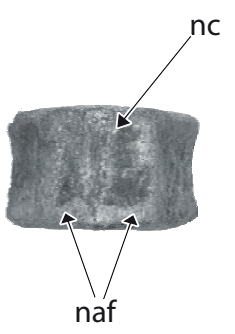

Figure 6. Vertebrae of Ichthyosauria indet. (A) Cervical vertebra PMO 229.733 in A1: anterior view, A2: left lateral view, A3: dorsal view. (B) Posteriormost dorsal vertebra PMO 229.735 in B1: anterior view, B2: left lateral view, B3: dorsal view. (C) Mid-caudal vertebra PMO 229.737 in C1: anterior view, C2: left lateral view, C3: dorsal view. (D) Posterior caudal vertebra PMO 229.738 in D1: anterior view, D2: left lateral view, D3: dorsal view. Abbreviations: dph - diapophysis, naf - neural arch facet, nc - neural canal, ncf - notochordal foramen, ncp notochordal pit. Scale $=1 \mathrm{~cm}$.

canal, while the diapophyses of B. leptorhynchus are located on the dorsal margin of the centrum, with the neural canal forming a depression between them (Dal Sasso \& Pinna, 1996). The holotype and only specimen of $B$. leptorhynchus has been compressed and the lateral morphology of the cervicals is unknown (Dal Sasso \& Pinna, 1996). In the cervicals of "Shastasaurus osmonti", the diapophyses are dorsoventrally longer than anteroposteriorly wide, and the diapophyses do not truncate either margin of the centra (Merriam, 1902, pl.
8, fig. 1). This is unlike the condition in PMO 229.733, where the diapophyses extend anteroposteriorly from the anterior margin to the posterior margin. The cervical PMO 229.733 is identical to the cervical PMU 24651 (Wiman, 1910, pl. 10, fig. 31) in having anteroposteriorly elongated diapophyses that become dorsoventrally elongated posteriorly.

Posterior dorsal vertebra (PMO 229.736, Fig. 6B). The posterior dorsal is lacking the posterior face of the 
centrum, but is otherwise uncompressed. In anterior view, the centrum is oval to triangular in outline. The outer portion of the articular face of the centrum is flat until about halfway towards the centre, where there is a relatively large notochordal pit as compared to the mediolateral width. The flattened lateral peripheral area of the articular face and triangular shape has been described for Cymbospondylus buchseri and Cymbospondylus petrinus (Merriam, 1908; Sander, 1989). The neural canal is slender and appears to be lacking the medial constriction along the anteroposterior length.

The margins of the diapophyses are tear-shaped; the dorsal rim is anteroposteriorly straight, but the lateral and ventral ends of the diapophyses slant anteroventrally. They are located close to the ventral margin of the centrum, and this ventral margin is nearly plane. The centrum resembles the posteriormost dorsal vertebrae of Cymbospondylus in the ventrally placed and rounded diapophyses (Merriam, 1908, figs. 24, 128 \& 131). A posterior dorsal was described for Californosaurus perrini; the specimen has ellipsoidal diapophyses which are lacking the anterior truncation (Merriam, 1902, pl. 7, Fig. 3).

Mid-caudal vertebra (PMO 229.737, Fig. 6C). The mid-caudal centrum lacks the dorsolateral margin of the posterior face, it is otherwise complete and uncompressed. The element is interpreted as a middle caudal based on the rounded diapophyses which are placed in contact with the anterior margin and on the dorsoventral midline (Merriam, 1908, fig. 132).

The outline in anterior view is hexagonal, as the greatest mediolateral width is directly on the dorsoventral midline, coinciding with the location of the diapophyses. These are rounded, in direct contact with the anterior face of the centrum and positioned midway dorsoventrally. Both the anterior and the posterior faces slope evenly medially until reaching the perforated notochordal pit. The ventral margin is mediolaterally narrow and flattened, possibly for the articulation to a hemal arch. The neural canal is slender and seems to be lacking a medial constriction.

A hexagonal shape of the caudal vertebrae is typical for Cymbospondylus, along with the flattened lateral peripheral area of the articular faces of the vertebrae (Merriam, 1908; Sander, 1992). The caudals of other large-sized Triassic ichthyosaurs have a similar dorsoventrally elongated, hexagonal shape (Dal Sasso \& Pinna, 1996, fig. 13G-H; Nicholls \& Manabe, 2001, 2004). The $\mathrm{H} / \mathrm{L}$ ratio of the middle caudal (2.38) is comparable to the $27^{\text {th }}$ caudal $(2.20)$ and identical to that of the $30^{\text {th }}$ caudal (2.38) of Cymbospondylus petrinus (Merriam, 1908). The numeration was estimated from the location of the femur of the specimen (Merriam, 1908, fig. 132). The flattened lateral peripheral area of the articular faces of the vertebrae was considered by Merriam (1908) to be a distinct feature of Cymbospondylus.
Posterior caudal vertebra (PMO 229.738, Fig. 6D). The posterior caudal is uncompressed and complete. The element is identified based on being anteroposteriorly short, lacking diapophyses, having a hexagonal outline and articular facets for a hemal arch. About two-thirds of both the anterior and the posterior faces show a peripheral lateral margin flattening, with a distinct deepening for the notochordal pit in the medial one-third of the centrum. It does not appear to perforate the vertebra.

The H/L ratio of Cymbospondylus petrinus has been described to decrease posteriorly, with the highest ratio of 2.59 for the $41^{\text {st }}$ caudal, decreasing to 2.42 for the $48^{\text {th }}$ caudal and 2.28 for the $53^{\text {rd }}$ caudal (Merriam, 1908). The $\mathrm{H} / \mathrm{L}$ ratio of PMO 229.738 is 2.29 , which might indicate a position far posteriorly in the vertebral column. It resembles the vertebra PIMUZ A/III 555 assigned to Cymbospondylus sp. by Sander (1992) in the hexagonal outline and the near-flat articular faces of the centrum.

The diapophyses are lacking, but the remnants can be observed midway dorsoventrally on the rim of the anterior margin as a small ridge. The neural canal is slim and of even mediolateral width throughout the anteroposterior length. The hemal arch facet is of approximately the same size as the neural arch facet.

?Right coracoid (PMO 230.178, Fig. 7A). The element appears to be part of an articular facet, where the entire margin of the element around this facet is weathered and broken. It is tentatively interpreted to be derived from a coracoid due to a small indentation covered in cortical bone on the dorsolateral ridge, interpreted as a remnant of the coracoid foramen (Merriam, 1908; Sander, 1989; Fröbisch et al., 2006). The coracoid foramen is considered diagnostic for Cymbospondylus (Merriam, 1908; Sander, 1989; Fröbisch et al., 2006), distinguishing the coracoids from Shastasaurus, Besanosaurus and Californosaurus (Merriam, 1902; McGowan, 1994; Dal Sasso \& Pinna, 1996). The coracoids of Cymbospondylus buchseri and Cymbospondylus petrinus are flat with thickened facets (Sander, 1989). The facet is thereby thought to be the glenoid facet as described by Merriam (1908). The coracoid foramen of Cymbospondylus buchseri and Cymbospondylus nichollsi is placed anterior to the glenoid facet, and it is therefore positioned as a right coracoid (Sander, 1989; Fröbisch et al., 2006).

The preserved part is a massive, tear-shaped facet which thickens ventrally. The dorsal surface is flat, with a radial surface bone structure. The dorsally expanded facet is surrounded by a distinct rim surrounding the articular surface. In dorsal view, medial to the rimmed facet, the element curves concavely and tapers out towards the thin medial margin. In ventral view, a part of the facet is ventrally expanded. The coracoid foramen is rounded, and the edges surrounding it are broken. The articular facet resembles that of the glenoid facet described for Cymbospondylus petrinus (Merriam, 


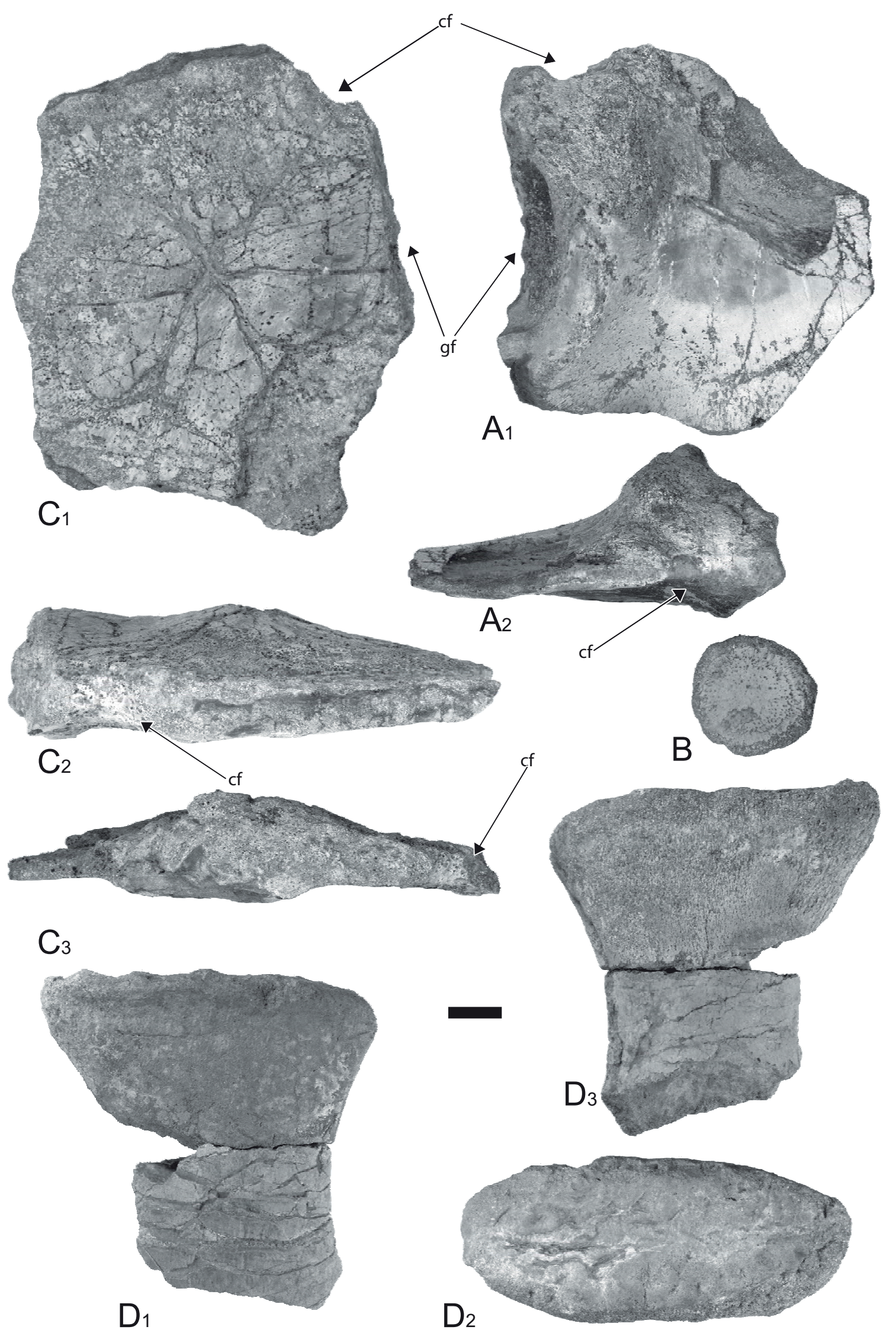

Figure 7. ?Coracoids and ?tibia of Ichthyosauria indet. (A) ?Right coracoid PMO 230.178 in A1: anterior view, A2: dorsal view. (B) A phalange PMO 230.180. (C) ?Left coracoid PMO 230.179 in C1: anterior view, C2: dorsal view, C3: mediolateral view. (D) ?Tibia PMO 229.784 in D1: ?dorsal/ventral view, D2: mediolateral view, D3: ?dorsal/ventral view. Abbreviations: $c f-$ coracoid foramen, $g f-$ glenoid facet. Scale $=1 \mathrm{~cm}$. 
1908, fig. 133), Cymbospondylus buchseri (Sander, 1989) and Cymbospondylus nichollsi (Fröbisch et al., 2006). The element could potentially be referred to cf., Cymbospondylus sp. due to the flat shape, thickened facet and the presence of a coracoid foramen. It is, however, referred to Ichthyosauria indet., due to its very fragmented nature. The ?right coracoid PMO 230.178 was collected in association with ?left coracoid PMO 230.179 , a phalange and a pair of elements interpreted as the possible scapular glenoid contributions.

?Left coracoid (PMO 230.179, Fig. 7C). The element is a flattened and round bone element. It is tentatively interpreted as derived from a coracoid due to the flattened shape, a thickened part which appears to be the remnant of a glenoid facet and a notch with preserved surface bone resembling the coracoid foramen of Cymbospondylus (Merriam, 1908; Sander, 1989; Fröbisch et al., 2006). It is positioned as a left coracoid based on the placement of the coracoid foramen, with comparisons to Cymbospondylus buchseri and Cymbospondylus nichollsi (Sander, 1989; Fröbisch et al., 2006). In ventral view, the remains of the glenoid facet can be extrapolated from a concavely curved surface which forms a thickened part of the lateral margin that enlarges posteriorly. In dorsal view, a part of the dorsally expanded facet is visible, similar to the condition in PMO 230.178. The bone surface shows radial lines spreading medially from the facet. Most of the margin is eroded, except for a small notch on the lateral margin of the facet. This is covered in cortical bone and is interpreted as the coracoid foramen. This foramen is identical in shape and size to the coracoid foramen found in ?right coracoid PMO 230.178 (Fig. 7A).

?Tibia (PMO 229.784, Fig. 7D). The element is an elongated, medially constricted limb bone which is broken mid-shaft. The specimen is tentatively interpreted as a dorsoventrally compressed tibia based on the anteroposteriorly elongated proximal articular facet. This is similar to the condition seen in the tibia of Besanosaurus leptorhynchus (Dal Sasso \& Pinna, 1996), Cymbospondylus petrinus (Merriam, 1908, figs. 96 \& pl. 12, fig. 5) and Xinminosaurus catactes (Jiang et al., 2008). It differs from the tibia of "Shastasaurus osmonti" (Merriam, 1908, pl. 16, fig. 6), in being more elongated and symmetrical. Both lateral margins of the element are concave. Along the most complete margin there is a dorsoventral groove, possibly due to compression or a remnant of a foramen. It is not possible to distinguish between the dorsal and the ventral surface of the element. The articular surface is well ossified and the anteroposteriorly facet is wide.

?Glenoid contribution of left scapula (PMO 230.181, Fig. 8A). The ?glenoid contribution is a massive teardropshaped bone fragment consisting of a flat articulate surface and a broken distal margin. The element is interpreted to be derived from the glenoid region of a scapula; the thick, flat articulate end is interpreted as a glenoid facet and the distal part of the facet appears to form a distal blade, similar to that described for Cymbospondylus petrinus (Merriam, 1908) and Cymbospondylus buchseri (Sander, 1989). The preferred interpretation is that it is derived from a left scapula, which is based on one of the distal surfaces of the facet (the medial surface) being flatter than the opposite surface (the lateral surface), where there is a notch created by the dorsal termination of the dorsolaterally expanded facet. In anterior view, the glenoid facet is almost flat, with minor rugosities possibly deriving from ossified cartilage forming the glenoid contribution. Three-fourths from the lateral edge, there is an anteroposterior ridge. Medial to this ridge, the surface forms a small concavity interpreted as the dorsalmost part of the coracoid facet (McGowan \& Motani, 2003). The margin posterior to the glenoid facet thickens laterally and thins distally. The edge is broken, revealing a tearshaped cross-section in distal view. In anterodorsal view, the lateral surface is convex and dorsally elevated, and the lateral edge of the glenoid facet is dorsolaterally expanded. The dorsal termination of the facet creates a distinct lateral notch.

?Glenoid contribution of right scapula (PMO 229.787, Fig. 8B). The ?glenoid contribution of the right scapula is a large bone element of near identical shape as that of the ?glenoid contribution of the left scapula. The margin medial to the anteroposterior ridge is missing on the articular surface. In anterior view, the articular surface of the glenoid facet is well ossified and is laterally expanded. The notch is less distinct due to weathering. In distal view, the outline of the broken margin is slender and tear-shaped. It shows a clear cross-section with the zonation of the inner cancellous bone and the outer $\sim 4 \mathrm{~mm}$ of cortical bone. The shape of the two glenoid contributions is mirrored, and this specimen is therefore interpreted to derive from the right scapula. However, PMO 229.787 seems to be of a slightly smaller size than the other ?glenoid contribution (Fig. 8A), and it is therefore uncertain if they formed an associated pair. Another element, PMO 230.153 (Fig. 8E), resembles that of the two ?glenoid contributions, but the element is too incomplete to determine this.

?Clavicle (PMO 229.793, Fig. 8C). The ?clavicle is elongated and broken in both ends, and the lateral surface is covered in cortical bone. It is interpreted to be a ?clavicle due to its oval cross-section, distinguishing it from a dorsal rib. It does not have a longitudinal groove as is seen in dorsal ribs of Shastasaurus (Merriam, 1902) and Cymbospondylus (Merriam, 1908). It resembles the size and elongated, slightly curving outline of the clavicle of Besanosaurus leptorhynchus (Dal Sasso \& Pinna, 1996) and that of "Shastasaurus osmonti" (Merriam, 1908, fig. 77). The shaft of the obliquely broken end expands slightly distally, away from the perpendicularly broken end. In cross-section, cancellous bone can be seen as growth circles surrounded by $\sim 1 \mathrm{~mm}$ of cortical bone. A shallow notch is located on one of the lateral margins between the two broken ends. 


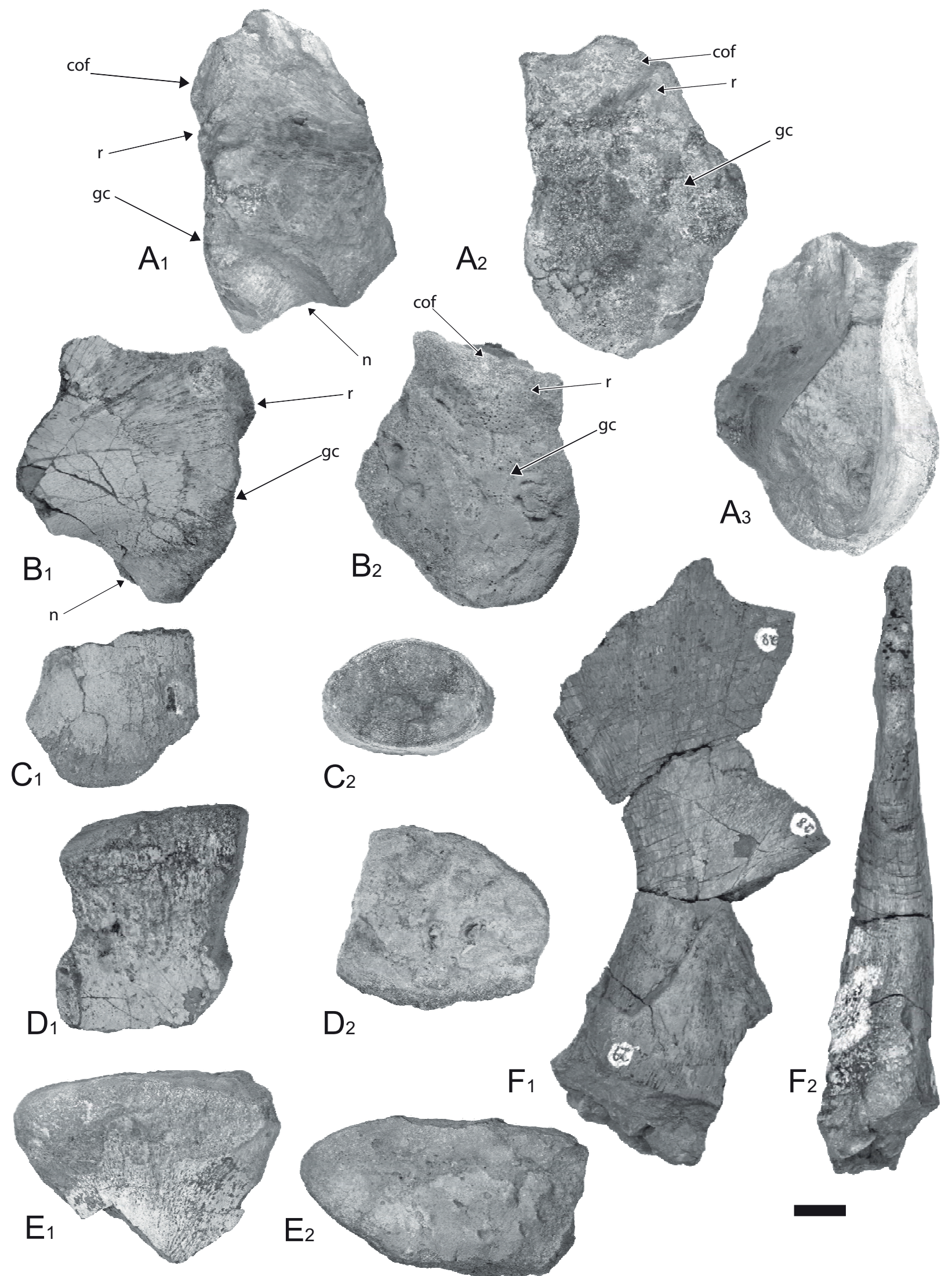

Figure 8. Girdle elements of Ichthyosauria indet. (A) ?Glenoid facet of a left scapula PMO 230.181 in A1: anterior view, A2: medial view, A3: lateral view to show tear-shaped cross-section. (B) ?Glenoid facet of a right scapula PMO 229.787 in B1: anterior view, B2: medial view. (C) ?Clavicle PMO 229.793 in C1: perpendicular view, C2: longitudinal view. (D) Unidentified bone element PMO 230.160 in D1: perpendicular view, D2: longitudinal view. (E) Unidentified bone element PMO 230.153 in E1: perpendicular view, E2: longitudinal view. (F) ?Blade of scapula PMO 230.182 in F1: perpendicular view, F2: longitudinal view. Abbreviations: cof - coracoid facet, gc - glenoid contribution, $n-$ notch, $r$ - ridge. Scale $=1 \mathrm{~cm}$. 
?Blade of scapula (PMO 230.182, Fig. 8F). The ?blade of the scapula is a flattened and elongated element, where only one margin is preserved. This is covered in cortical bone, and curves concavely. The element is interpreted to be derived from the blade of a scapula as it resembles the elongated, flattened and curved shape of the scapular blade of "Shastasaurus alexandrae" (Merriam, 1902, pl. 12), "Shastasaurus osmonti" (Merriam, 1902, pl. 10, fig. 4), Cymbospondylus petrinus (Merriam, 1908, fig. 76) or Cymbospondylus buchseri (Sander, 1989). It is flattened anteroposteriorly and elongated dorsoventrally. The distal blade is incomplete, with the distalmost part preserved and having a thickness of approximately 5 $\mathrm{mm}$. The anterior end is significantly more robust with a thickness of $23 \mathrm{~mm}$. The preserved bone surface on the depicted side of the anterior half of the element curves concavely and thickens anteroposteriorly, and is interpreted as the distalmost part of the glenoid facet. PMO 230.182 was found associated with an element potentially thought to be a glenoid facet of a scapula (PMO 230.153, Fig. 8E).

Pelvic girdle (PMO 230.163-230.172, Figs. 9 \& 10). The material was found in possible association with a mid-dorsal vertebra assigned to Cymbospondylus. Four rounded podial elements are interpreted as phalanges (Fig. 10).

?Ischium (PMO 230.163, Fig. 9A). The ?ischium is a large, plate-like bone element. The specimen is identified as an ischium based on the element's large size and hatchet shape, resembling that of Besanosaurus leptorhynchus (Dal Sasso \& Pinna, 1996, fig. 17C), Cymbospondylus petrinus (Merriam, 1908, fig. 70) and Californosaurus perrini (Merriam, 1902, pl. 5, fig. 4). Triassic ichthyopterygians are characterised as having ischia that are near equal in width and length (McGowan \& Motani, 2003), and have a flat and thickened anterior margin, a convex lateral margin and a concave medial margin (Merriam, 1902, 1908; Dal Sasso \& Pinna, 1996), and the ischium is oriented accordingly. The mediolateral width of PMO 230.163 is slightly less than its anteroposterior length, and the medial margin is smooth and concave.Merriam (1908) defined the ischia of Cymbospondylus as having the greatest transverse width compared to anteroposterior length. This is, however, not strongly supported by the measurements provided in Merriam (1908), and therefore may not be a diagnostic feature.

The ?ischium resembles the ischia described for Besanosaurus leptorhynchus (Dal Sasso \& Pinna, 1996, figs. 17C \& 21A), Cymbospondylus petrinus (Merriam, 1908, fig. 134) and Californosaurus perrini (Merriam, 1902, pl. 5, fig. 4). The ischium described herein has a transverse width to anteroposterior length $(\mathrm{W} / \mathrm{L})$ ratio of 0.78 . This falls between the ischium of C. petrinus UCMP 9950 with 0.88 (although it is 0.78 when measured from Merriam, 1908, fig. 134) and 0.68 for C. petrinus UCMP 99470.68 (measured from Merriam, 1908, fig. 3). The ischium of type specimen UCMP 9086 of C. perrini closely resembles the shape of PMO 230.163 (Merriam, 1902, pl. 5, fig. 4; 1908, fig. 145), with a W/L ratio of 0.92 (exact location of measurements was not provided).

The element is thickest in the medial direction, and thinnest in the posterolateral end. The posterior margin is well ossified and expands mediolaterally. The convex curvature continues until the anteroposterior midline, where the ossification ends and there is a small notch covered in cortical bone (Fig. 9A $\mathrm{A}_{1}$. Anterior to this notch, a fragment of the lateral margin is missing. In anterior view, the acetabular facet is ellipsoidal with the thickness increasing in the medial direction, and well ossified with a pitted surface. The lateral end of the acetabular facet extends posterolaterally, and there appears to have been a slight concavity along the lateral margin between the acetabular facet and the notch.

?Pubis (PMO 230.164, Fig. 9B). The ?pubis is uncompressed, but fragments are missing along both margins in the longitudinal direction. The specimen is interpreted as a pubis based on the overall shape and size which resembles Besanosaurus leptorhynchus (Dal Sasso \& Pinna, 1996, fig. 17C) and "Shastasaurus osmonti" (Merriam, 1908, fig. 73), and the presence of what seems to be an obturator foramen or notch (Merriam, 1908). The positioning of the obturator foramen on the posterolateral margin and the concave medial margin of the pubis has been described for Shastasaurus, Cymbospondylus and Besanosaurus (Merriam, 1895, 1902, 1908; Dal Sasso \& Pinna, 1996), and the specimen is therefore oriented likewise herein. The pubis is dorsoventrally thicker and more massive than the ischium. In anterior view, the margin forms a near mediolateral flat surface. The margin surface is rugose, suggesting the presence of connective tissue. The anterior margin is thickest along the mediolateral midline. The posterior third of the medial margin is preserved and convex. The ossified margin continues posteriorly to the acetabular facet, which is ellipsoidal and thickens laterally. The acetabular facet of the pubis is approximately one-third thicker than the acetabular facet of the ischium. On the mediolateral midline, there is a slight depression or notch on the dorsal margin of the acetabular facet. The lateral end of the acetabular facet is missing. However, directly anterior to the end of the facet, a portion of the lateral rim is preserved. The preserved surface of the lateral rim is smooth and concave, and situated several centimetres medial to what is preserved of the anterolateral margin. The posterior edge of the preserved anterolateral margin is convex and curves laterally, suggesting that a significant bend may have been present where the lateral margin is missing on the specimen.

The smooth concavity is interpreted be a remnant of the obturator foramen, typical for many Triassic ichthyosaurs 

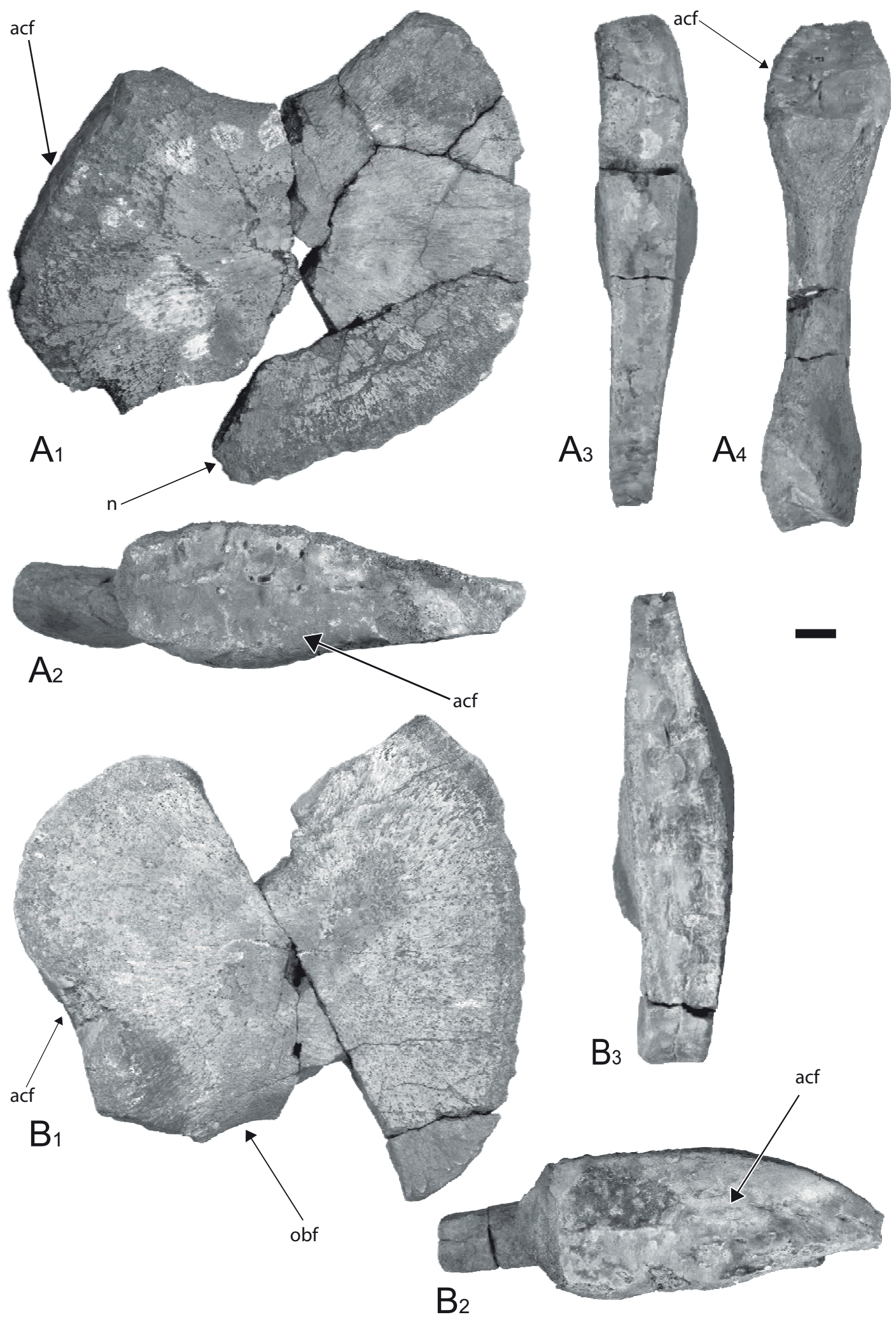

Figure 9. ?Ischium and ?pubis of Ichthyosauria indet. (A) ?Ischium PMO 230.163 in A1: dorsal view, A2: acetabular view, A3: posterior view, A4: medial view. (B) ?Pubis PMO 230.164 in B1: dorsal view, B2: acetabular view, B3: anterior view. Abbreviations: acf - acetabular facet, obf - obturator foramen. Scale $=1 \mathrm{~cm}$. 


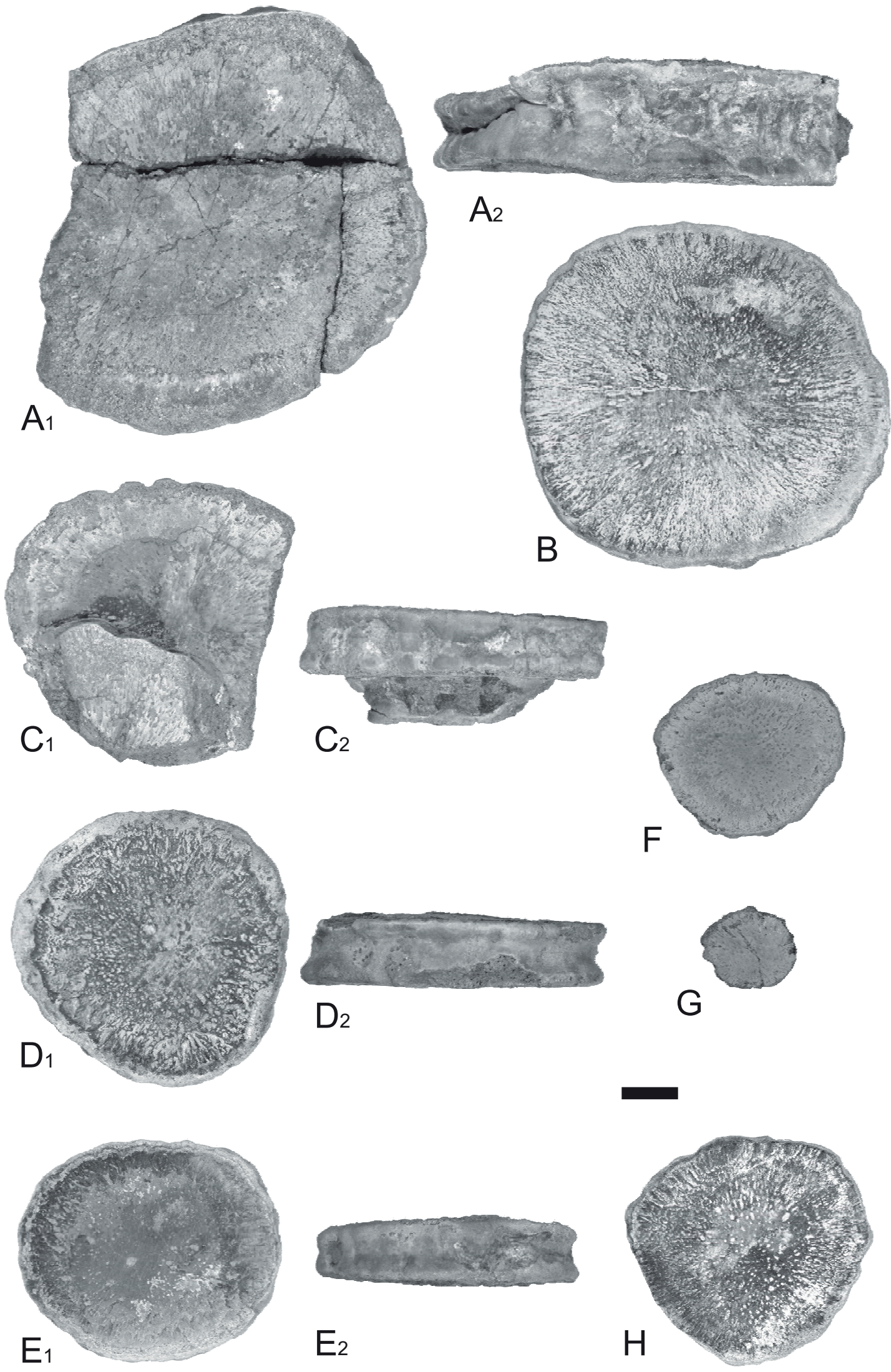

Figure 10. Phalanges found in association with ?ischium PMO 230.163 and ?pubis PMO 230.164. (A) PMO 230.166. (B) PMO 230.167. (C) PMO 230.165. (D) PMO 230.169. (E) PMO 230.172. (F) PMO 230.170. (G) 230.168. (H) PMO 230.171. Scale $=1 \mathrm{~cm}$. 
(Merriam, 1895, 1902, 1903, 1908; Dal Sasso \& Pinna, 1996). It is not possible to determine whether it is enclosed as in Cymbospondylus petrinus (Merriam, 1908, fig. 70) and Toretocnemus (Merriam, 1903), or hook-like as in "Shastasaurus osmonti" (Merriam, 1908, fig. 73), Besanosaurus leptorhynchus (Dal Sasso \& Pinna, 1996, figs. 17C \& 21A) and Californosaurus perrini (Merriam, 1908, fig. 72). However, Merriam (1908) noted that the obturator foramen was incompletely surrounded in some specimens of $C$. petrinus, as also seen in Shastasaurus. The outline of the pubis resembles that of the pubis of $B$. leptorhynchus (Dal Sasso \& Pinna, 1996, fig. 17C) and “S. osmonti" (Merriam, 1908, fig. 73).

?Tibia (PMO 230.157, Fig. 11A). The specimen lacks part of the lateral margin on the articular surface of both ends. It is interpreted as a tibia based on its hourglass shape and the anteroposteriorly elongated articular facets, similar to the condition seen in the tibia of Besanosaurus leptorhynchus (Dal Sasso \& Pinna, 1996), Cymbospondylus petrinus (Merriam, 1908, fig. 96 \& pl. 12, fig. 5) and "Shastasaurus osmonti" (Merriam, 1908, fig. 101). The specimen bears a strong resemblance to SVT 222, referred to an Omphalosaurus (= Pessopteryx) nisseri tibia by Mazin (1983, fig. 7). Identical elements were pictured by Wiman (1910) as unidentifiable bone (pl. 9, figs. 9-11). Two of these elements (Wiman, 1910, pl. 9, figs. 9-10), were referred to as tibia of $B$. leptorhyncus by McGowan \& Motani (2003). The preserved articular surfaces are well ossified, and the element is anteroposteriorly constricted mid-shaft. One of the lateral surfaces has a foramen on the proximodistal midline.

Neural arch PMO (229.790, Fig. 11B). The neural arch is near-complete and practically undistorted, except for the broken ends of the pedicles. In anterior view, the pedicles are separated by a wide neural canal; the mediolateral distance between them is wider than that of the neural spine. The postzygapophyses appear to be paired, typical for non-neoichthyosaurian ichthyosaurs (Maisch \& Matzke, 2000). They are divided by a groove, which could be an artefact of preservation. It could also be a foramen similar to what was described for the "shastasaurid- or cymbospondylid-like neural arch" by Fischer et al. (2014). The prezygapophysis is situated directly dorsal to the neural canal, but the features are completely eroded and only the breakage point from where it was situated is visible. The neural spine has an even dorsoventral thickness similar to "Shastasaurus osmonti" (Merriam, 1908, figs. 31 \& 33), but unlike Cymbospondylus (Maisch \& Matzke, 2000), "Shastasaurus pacificus" (McGowan, 1994), Callawayia neoscapularis, Shonisaurus sikanniensis and "Shastasaurus altispinus" (Merriam, 1908; Nicholls \& Manabe, 2001, 2004). The variation in dorsoventral thickness of "S. altispinus" is however very slight (Merriam, 1908). There is no apparent thickening in the neural spines of the Cymbospondylus sp. from Spitsbergen (Sander, 1992).
An even thickness of the neural spine is also known in Mixosaurus and Temnodontosaurus (Maisch \& Matzke, 2000), and may not be useful as a distinguishing feature.

Jaw (PMO 230.173-230.176, Fig. 12). The jaw assemblage consists of 24 elements found in association. Most of the elements bear relatively large (diameter 8-9 $\mathrm{mm}$ ) teeth. No tooth crowns are preserved, and striations can be observed at the base. The jaw elements are fractured, but uncompressed. The maximum preserved jaw depth is approximately $37 \mathrm{~mm}$. Three larger elements (Fig. 12A-C), have been reassembled from smaller pieces. Two of these large elements are possibly articulated, comprising the anteriormost part of a snout. They are interpreted as parts of a premaxilla based on the reduced symphysis in the anteriormost specimen and the presence of an anteroposterior labial groove in both specimens. The anteroposterior labial groove seen in the tip of the snout is interpreted as the articulation for the nasals, as the nasals of ichthyosaurs extend well anteriorly in the snout, ventrally to the premaxillae (McGowan \& Motani, 2003). The anterior tip of the premaxilla slants dorsally and is rounded, as is also seen in Cymbospondylus petrinus (Merriam, 1908). The anterior extent of the nasals has not been described for Shastasaurus (Merriam, 1902; McGowan, 1994) or for Cymbospondylus (Merriam, 1908). The anterior preserved part of the rostrum in Cymbospondylus buchseri consists of the premaxilla and nasal (Sander, 1989). However, it is not clear how far anterior in the snout this element was originally positioned (Sander, 1989).

The dentition is thecodont, and there seems to be a shallow groove in which the teeth are placed in individual sockets, as described for Cymbospondylus buchseri (Sander, 1989). They are consistent in size, and no replacement teeth or resorption pits can be observed. The teeth are homodont, conical and with coarse longitudinal striations from the root and towards the apex.

?Ilium (PMO 229.785, Fig. 13). The specimen is complete but weathered and transversely flattened. The outline closely resembles that of the ilium from Besanosaurus leptorhynchus (Dal Sasso \& Pinna, 1996, fig. 21A) and "Shastasaurus osmonti" (Merriam, 1908, fig. 73), and the element is therefore tentatively referred to as an ilium. It has a concave dorsoventral margin which is herein oriented as the anterior margin, based on the condition in B. leptorhynchus (Dal Sasso \& Pinna, 1996, fig. 21A) and "S. osmonti" (Merriam, 1908, fig. 73). The acetabular end has two facets. The posteriorly slanted anterior facet has two grooves that are parallel and run in the anteroposterior direction, while the anterior facet forms a dorsoventrally oriented tear-shaped notch. The anterior dorsoventral margin is anterioposteriorly concave. The dorsal margin is rugose and nearly anteroposteriorly flat. It is eroded along the entire anteroposterior length on one of the lateral margins. 


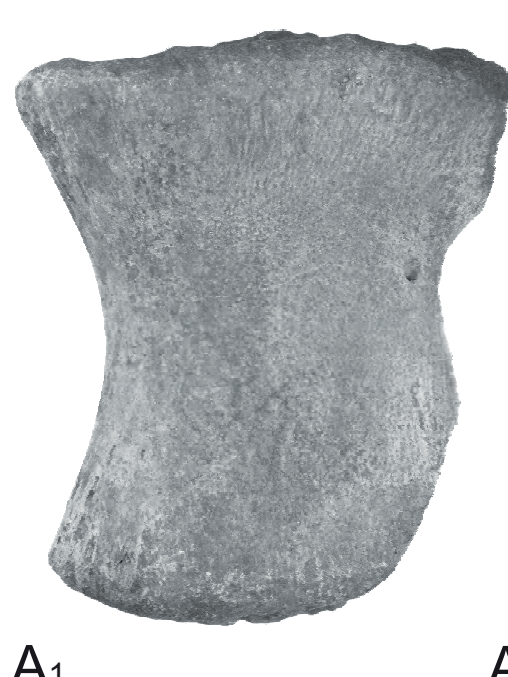

$\mathrm{A}_{1}$

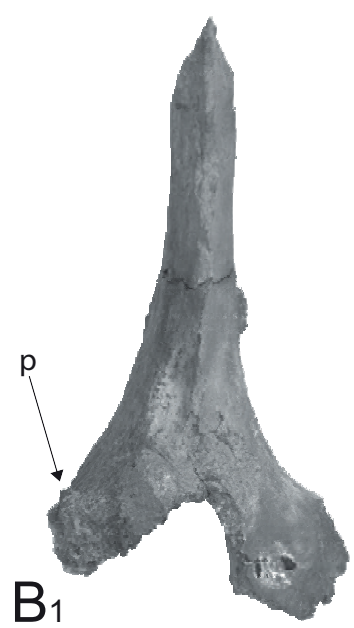

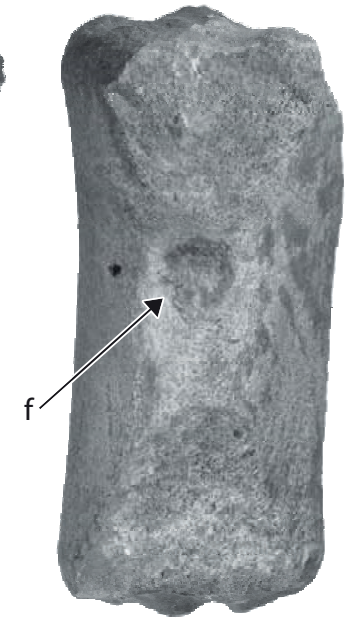

$\mathrm{A}_{2}$

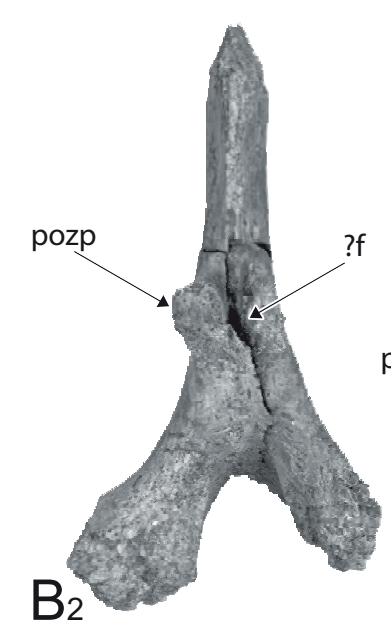

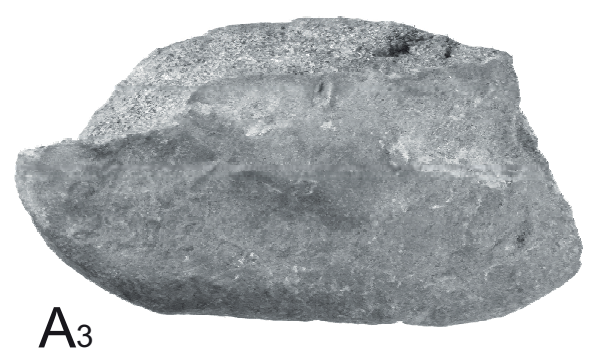

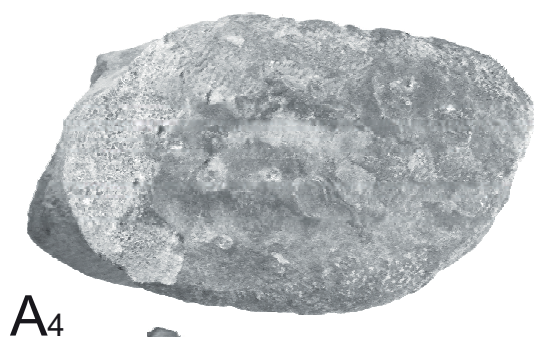

$\mathrm{A}_{4}$

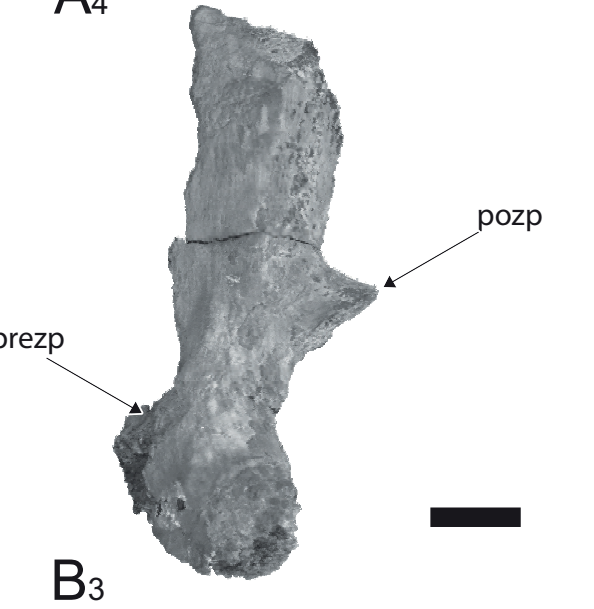

Figure 11. Limb element and neural arch of Ichthyosauria indet. (A) ?Tibia PMO 230.157 in A1: ?dorsal/ventral view, A2: ?medial/lateral view, A3: ?distal/proximal view, A4: ?distal/proximal view. (B) Neural arch PMO 229.791 in B1: anterior view, B2: posterior view, B3: left lateral view. Abbreviations: $f$-foramen, $p$-pedicle, pozp - postzygapophysis, prezp - prezygapophysis. Scale = $1 \mathrm{~cm}$.

Ventrally on the lateral surface (Fig. 13A $)$, there is a slightly laterally expanded and rounded, but weathered elevation. This might be a remnant of an anterior process, similar to the condition seen in Cymbospondylus petrinus (Merriam, 1908). The ?ilium has a dorsoventral height / acetabular anteroposterior length ratio of 2.53, comparable to 2.43 in B. leptorhynchus (Dal Sasso \& Pinna, 1996). The dorsal end is too weathered to describe in detail. The ?ilium is lacking the expanded acetabular facet and the posteriorly elongated blade described from C. petrinus (Merriam, 1908). Overall, the shape and size resembles that of specimen UCMP 9608 referred to "S. osmonti" (Merriam, 1908, pl. 16, fig. 4). This ilium measures $110 \mathrm{~mm}$ in dorsoacetabular length and $60 \mathrm{~mm}$ in anteroposterior width of the dorsal margin (Merriam, 1908). It differs from Californosaurus perrini, which has a tubercle on the posterior margin (Merriam, 1908).

\section{Discussion}

For the first time since 1910, new Early Triassic ichthyopterygian material has been systematically collected and described from the Lower Saurian niveau of Marmierfjellet, Spitsbergen. The Flowerdalen bone horizons have now been correlated to the modern stratigraphy, and a detailed log of the Lower Saurian niveau is provided as part of this study. Material referable to the genera Cymbospondylus sp. and Pessopteryx nisseri from the Lower Saurian niveau have been diagnosed on vertebrae and humeri, respectively. Consequentially, the lack of overlapping, articulated material hinders further analysis of their phylogenetic relationship. However, the abundant material collected from the Lower Saurian niveau provides clear evidence that derived, largesized ichthyosaurs had evolved by the Olenekian Stage. The indeterminate ichthyosaurian material described herein shares traits with Cymbospondylus nichollsi, 

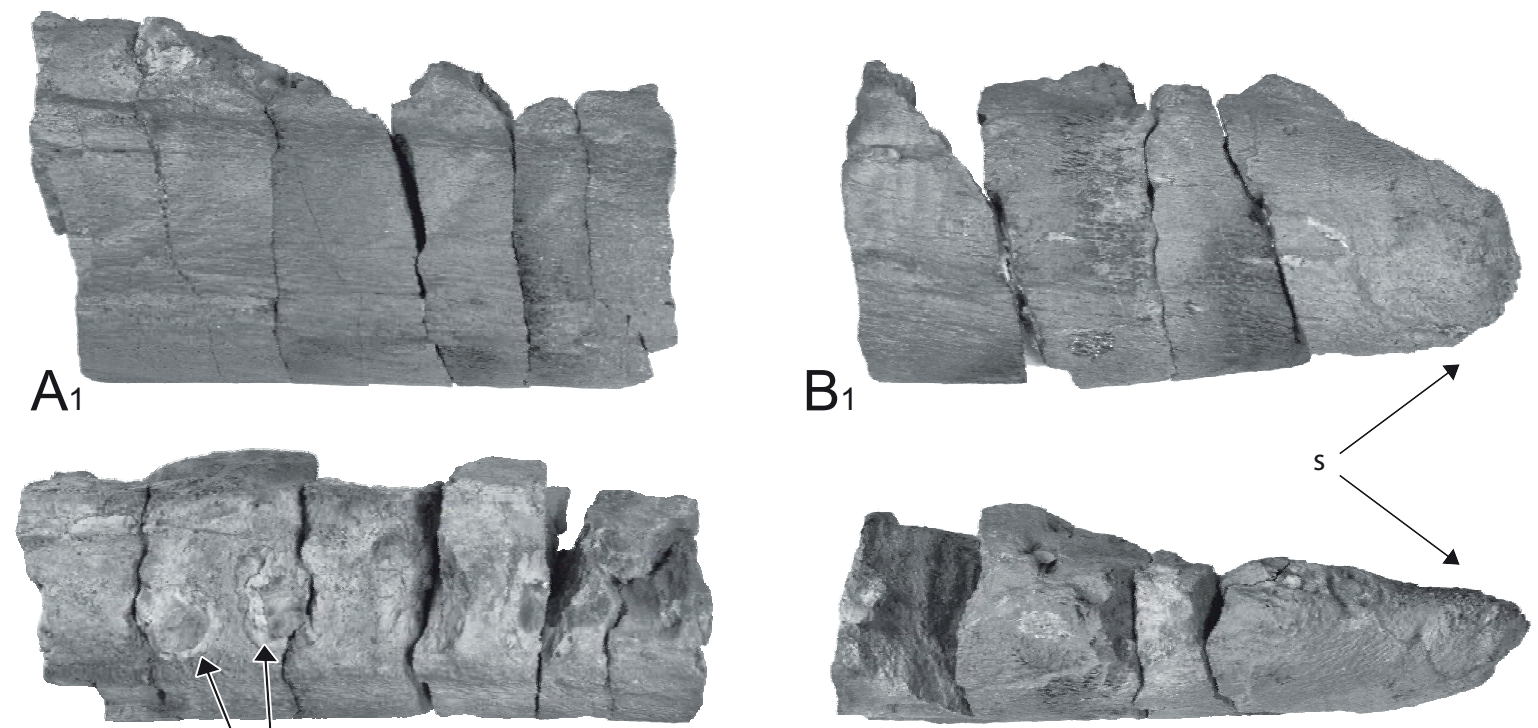

$\mathrm{B}_{2}$

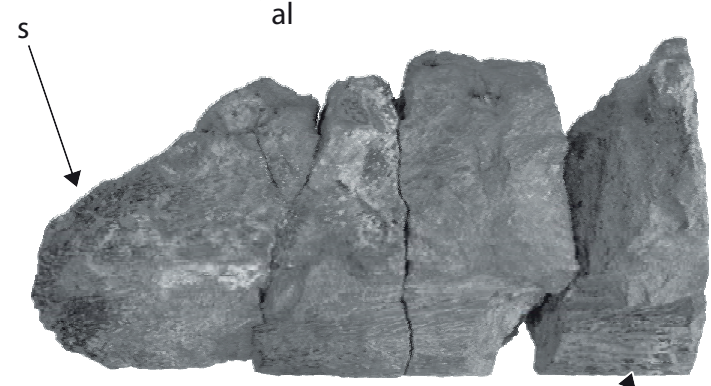

$\mathrm{B}_{3}$
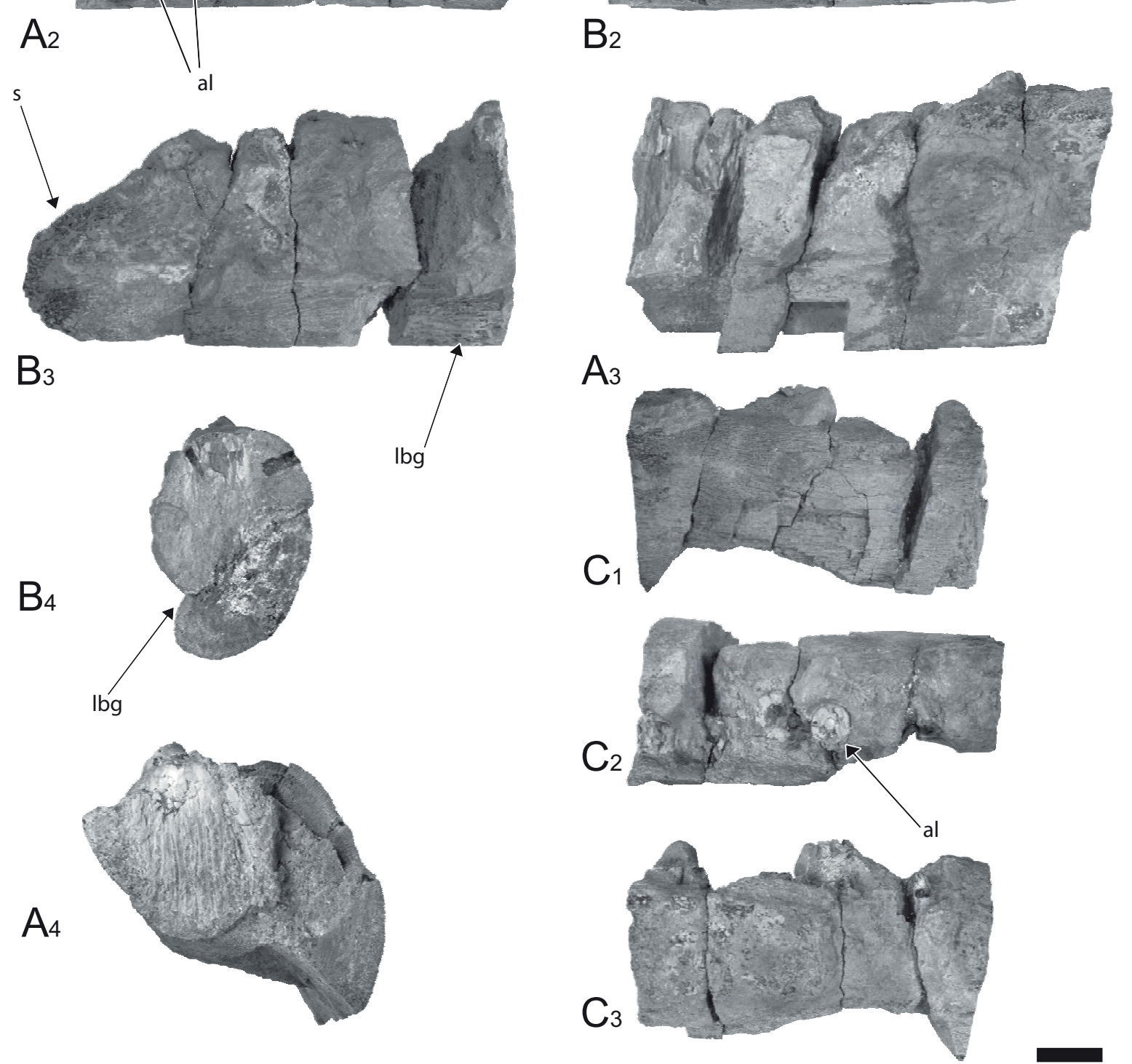

Figure 12. Partly articulated jaw of Ichthyosauria indet. (A) Middle part of ?premaxilla PMO 230.175, in A1: lateral view, A2: ventral view, A3: medial view, A4: posterior view. (B) Anterior end of ?premaxilla PMO 230.173 in B1: lateral view, B2: ventral view, B3: medial view, B4: posterior view. (C) Unidentified jaw element PMO 230.174 in C1: lateral view, C2: ventral or dorsal view, C3: medial view. Abbreviations: al - alveoli with broken teeth, lbg - labial groove, $s-$ symphysis. Scale $=1 \mathrm{~cm}$. 
Cymbospondylus petrinus, Cymbospondylus buchseri, Besanosaurus leptorhynchus, "Shastasaurus osmonti", "Shastasaurus alexandrae", Californosaurus perrini and Xinminosaurus catactes.

\section{What is Pessopteryx nisseri?}

One of the bigger controversies surrounding the Early Triassic ichthyopterygians from Svalbard described by Wiman (1910) has been the status of Pessopteryx, the relationship to Omphalosaurus and their respective positions within the Ichthyopterygia (for more details, see Motani, 1999, 2000). The phylogenetic position of Omphalosaurus remains in a state of flux, nonetheless, the Lower Saurian ichthyosaurian material in this study can be distinguished from Omphalosaurus based on the bone histology; the vertebrae of Omphalosaurus are poorly ossified with endochondral bone on the articular surfaces of the vertebrae (Sander \& Faber, 2003; but see Ekeheien et al., 2018). The large ichthyosaur material described here only displays endochondral bone on the diapophyses and on the facets for the neural arches.

The presence of humeri referable to Pessopteryx nisseri was recognised through comparisons with the lecto-
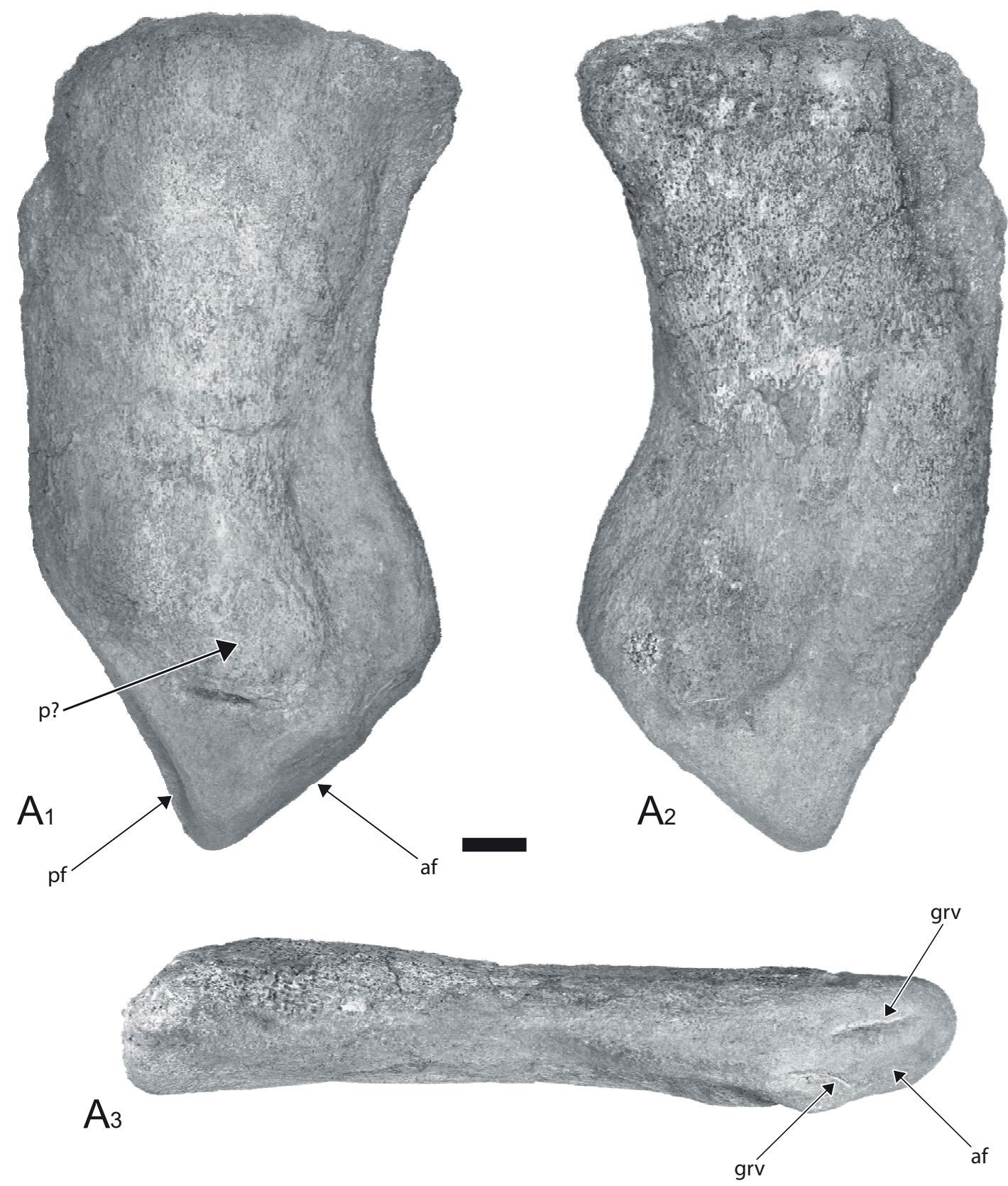

Figure 13. ?Ilium of Ichthyosauria indet. (A) PMO 229.785, in A1: ?medial/lateral view, A2: ?medial/lateral view, A3: anterior view. Abbreviations: af - anterior facet, grv-groove, $p$ - process, $p f$ - posterior facet. Scale $=1 \mathrm{~cm}$. 
and paralectotype material of $P$. nisseri housed in the Palaeontological Collection, Museum of Evolution, Uppsala University, Sweden. The near equal proximal and distal anteroposterior widths of the humeri of $P$. nisseri described herein resemble the condition found in Besanosaurus leptorhynchus (Dal Sasso \& Pinna, 1996), Cymbospondylus buchseri (Sander, 1989), "Shastasaurus osmonti" (Merriam, 1902), Californosaurus perrini (Merriam, 1908), Shonisaurus sikanniensis (Nicholls \& Manabe, 2004) and Callawayia neoscapularis (McGowan, 1994). The humeri referred to $P$. nisseri are lacking the notching of the anterior margin, distinguishing $P$. nisseri from B. leptorhynchus, C. neoscapularis, "S. osmonti" and C. perrini. They do, however, share the triangular shape of the distal surface of the humerus seen in Cymbospondylus petrinus (Merriam, 1908; Massare \& Callaway, 1994) and "S. osmonti" (Merriam, 1902).

Today, Pessopteryx nisseri is considered to be the valid species for the ichthyopterygian material from Wiman's hypodigm (Motani, 1999; McGowan \& Motani, 2003; Maisch, 2010; Maxwell \& Kear, 2013). Wiman (1910) stated that the assemblages of $P$. nisseri were collected as loose elements, which is also true for the material collected from the Lower Saurian niveau described herein. As a result, no specimen assemblages can securely be determined as articulated, and only the humeri described in this study can be confidently assigned to $P$. nisseri. Additionally, the lectotype and the paralectotypes of $P$. nisseri have been extensively reconstructed. Still, they overlap and in combination they have the diagnostic features of the humerus preserved. Much of the remainder of the material described by Wiman (1910) as P. nisseri is undiagnostic. As P. nisseri is now defined on humeri and to avoid making it a wastebasket taxon for ichthyopterygian remains from the Lower Saurian niveau, it is not possible to assign any material other than humeri to $P$. nisseri without the discovery of indisputably articulated specimens.

\section{Two coexisting large-sized ichthyosaur genera from the Lower Saurian niveau?}

In the strict consensus tree presented by Moon (2017), Cymbospondylus is resolved as a monophyletic group, with Pessopteryx nisseri placed as the sister taxon in the $50 \%$ majority rule consensus tree.

The identification of Cymbospondylus sp. was based on 36 dorsal vertebrae displaying the characteristic truncation of the diapophyses on the anterior margin of the centrum, a concave atlas and two axes (Merriam, 1908; Sander, 1989, 1992, 1997; Fröbisch et al., 2006). Another possible Early Triassic Cymbospondylus has previously been described from Idaho, based on a loose scree assemblage of five vertebrae, an unidentifiable bone and the distal part of a left humerus (Massare \& Callaway, 1994). The hexagonal shape of one of the caudals and the anterior truncation of the diapophyses of the dorsal vertebra identified those elements as Cymbospondylus sp; however, the remaining elements were also given this assignment despite being undiagnostic (Massare \& Callaway, 1994). The material described herein from the Lower Saurian niveau is better preserved than the Cymbospondylus material from Idaho. On the fragmented humerus, the anteroposterior lengths could be measured for the articular facets and the anteroposterior distal width and the shape was compared to that of Cymbospondylus petrinus (Massare \& Callaway, 1994). This specimen is $\sim 50 \%$ larger than the largest humerus (PMO 229.782) described here.

The material described herein is not the first identification of Cymbospondylus from Svalbard; a Middle Triassic Cymbospondylus specimen from the Upper Saurian niveau was described by Sander (1992) based on a string of 17 dorsal vertebrae from the Botneheia mountain and two isolated centra from Wichebukta on Spitsbergen. PMO 162.003 (= PIMUZ A/III 496 in Sander 1992, see Lindemann, 1998) consists of semi-articulated dorsal vertebrae with anteriorly truncating diapophyses. The specimen was suggested to have synonymy with Pessosaurus by Sander \& Faber (1998), which was rejected by Maxwell \& Kear (2013) due to the lack of overlapping material.

Although parts of the collected and identified material in this study have been assigned to two taxa, of the more than 400 fragmentary limb elements and 250 skull fragments assigned to Ichthyosauria indet., none of the material seems to indicate that there are two largesized taxa in the sample; e.g., two large-sized humeral morphotypes, convex atlases or dorsal vertebrae that do not show the anterior truncation of the diapophyses. Vertebrae attributable to Cymbospondylus sp. are well represented in the Lower Saurian niveau, and the six identified humeri are smaller, but similar to previously described material of Pessopteryx nisseri.

Comparing the humeral morphology of Pessopteryx nisseri to the Middle Triassic species of Cymbospondylus is complicated by the fact that the humeri are only known from the humeri of Cymbospondylus petrinus (Merriam, 1908) and a left humerus of Cymbospondylus buchseri (Sander, 1989), and that these show rather large morphological differences. The humerus of $C$. petrinus is elongated, with a constricted shaft and an expanded distal end, while the humerus of C. buchseri is nearly isometric (see comparison in Sander, 1989, fig. 8). The proximal end of the humerus of $C$. buchseri is slightly anteroposteriorly shorter than the distal end, both articular surfaces appear to have been covered in cartilage and the anterior margin is nearly straight (Sander, 1989), similar to the condition seen in the $P$. nisseri humeri described herein. However, $P$. nisseri does not have the thickened posterior margin described for C. buchseri (Sander, 1989). McGowan \& Motani (2003) characterised Cymbospondylus as having 
a humerus with a slightly concave anterior flange, with Ji et al. (2015) suggesting that Cymbospondylus could be diagnosed on having a humerus of near equal distal and proximal width. These traits are similar to the humeri of P. nisseri, however, Motani (1999), Maisch \& Matzke (2000) and Fröbisch et al. (2006) did not include humeral traits in their diagnosis of Cymbospondylus. Until the humeral morphology of Cymbospondylus is better understood, these traits are therefore not considered consistent and distinguishing enough for a referral of the P. nisseri humeri.

All the dorsal vertebrae described in this study show the truncation of the diapophyses on the anterior centrum margin, considered diagnostic for Cymbospondylus (Merriam, 1908; Huene, 1916; Sander, 1989, 1992, 1997, 2000; Fröbisch et al., 2006). Dorsal vertebrae showing the anterior truncation of the diapophyses were also identified in the Wiman collections of the Paleontological Collection, Museum of Evolution, Uppsala University, Sweden (PMU, pers.obs. VSE). The possibility exists that the anterior truncation of the diapophyses on the centrum margin is a less unique feature for the Early Triassic genera than previously shown for the Middle Triassic ichthyosaurs. Accordingly, P. nisseri could display this feature of the diapophyses on the dorsal centra without being closely related to Cymbospondylus, as the dorsal vertebrae of many Triassic genera have dorsoventrally elongated diapophyses and lack parapophyses (Merriam, 1908). The diapophyses on the dorsal vertebrae of "Shastasaurus altispinus" (Merriam, 1902, pl. 15, fig. 1), "Shastasaurus osmonti" (Merriam, 1902, pl. 8, figs. 3 \& 5) and Californosaurus perrini (Merriam, 1902, pl. 7, fig. 2) are also anteriorly slanted, although they never touch the anterior margin of the centrum, as was described in detail by Merriam (1908).

As all dorsal vertebrae show the anterior truncation of the diapophyses, it is probable that the cervical and caudal vertebrae could also belong to Cymbospondylus. However, as they are undiagnostic and were collected as isolated elements, we assign them to Ichthyosauria indet. Assemblages of bone elements collected include a possibly associated pelvic girdle (found in association with Cymbospondylus dorsals), large jaw fragments, shoulder girdles and numerous vertebrae from mid- to large-sized ichthyosaurs. Pessopteryx nisseri and the species of Cymbospondylus are currently not represented by overlapping material, and it is therefore not possible to establish the phylogenetic relationship between them without the discovery of unequivocally articulated material. Independent of their phylogenetic relationship, the large-sized ichthyosaur material described in this study is unequivocal evidence that the evolution of largebodied ichthyosaurians occurred earlier than previously thought; before the late Middle and Late Triassic. Additional Svalbard material has been collected and is currently under study.
Acknowledgements. Thanks to Spitsbergen Travel, National Geographic (grants GEFNE158-15; GEFNE 108-14), Bayerngas Norge, Tullow Oil and CGG for financing fieldwork 2014-16. A special thanks to all volunteers that participated in the three field seasons; Tommy Wensås, Øyvind Enger, Bjørn Lund, Stig Larsen, Magne Høyberget, Erik Tunstad, Lena Kristiansen, Charlotte Sletten Bjorå, Julie Rousseau and Krzysztof Hryniewicz. Many thanks also to Achim Reisdorf, University of Basel, Prof. Hans Arne Nakrem, University of Oslo, Prof. Martin Sander, University of Bonn, Prof. Patrick Druckenmiller, University of Alaska and to Franz-Josef Lindemann, University of Oslo who all contributed greatly with their help and insight. Our sincere thanks go to the reviewers for their insightful comments which greatly improved the manuscript.

\section{References}

Benton, M.J. \& Twitchett, R.J. 2003: How to kill (almost) all life: the end-Permian extinction event. Trends in Ecology \& Evolution 18, 358-365. https://doi.org/10.1016/S0169-5347(03)00093-4.

Benton, M.J., Zhang, Q., Hu, S., Chen, Z.Q., Wen, W., Liu, J., Huang, J., Zhou, C., Xie, T., Tong, J. \& Choo, B. 2013: Exceptional vertebrate biotas from the Triassic of China, and the expansion of marine ecosystems after the Permo-Triassic mass extinction. Earth-Science Reviews 125, 199-243.

https://doi.org/10.1016/j.earscirev.2013.05.014.

Blainville, H.M.D.d. 1835: Description de quelques espèces de reptiles de la Californie: précédée de l'analyse d'un systéme général d'erpétologie et d'amphibiologie. Nouvelles Annales du Muséum d'Histoire Naturelle 4, 233-296.

Dagys, A.S. \& Weitschat, W. 1993: Correlation of the Boreal Triassic. Mitteilungen aus dem Geologisch-Paläontologischen Institut der Universität Hamburg 75, 249-256.

Dal Sasso, C. \& Pinna, G. 1996: Besanosaurus leptorhynchus n. gen. n. sp., a new shastasaurid ichthyosaur from the Middle Triassic of Besano (Lombardy, N. Italy). Paleontologia Lombarda 4, 3-23.

Dames, W.B. 1895: Über die Ichthyopterygier der Triasformation. Sitzungsberichte der Akademie der Wissenschaften zu Berlin 46, 1045-1050.

Dunham, R.J. 1962: Classification of carbonate rocks according to depositional textures. Classification of Carbonate Rocks $-A$ Symposium, 108-121.

Ekeheien, C.P., Delsett, L.L., Roberts, A.J. \& Hurum, J.H. 2018: Preliminary report on ichthyopterygian elements from the Early Triassic (Spathian) of Spitsbergen. Norwegian Journal of Geology 98, 219-237. https://dx.doi.org/10.17850/njg98-2-07.

Fischer, V., Cappetta, H., Vincent, P., Garcia, G., Goolaerts, S., Martin, J.E., Roggero, D. \& Valentin, X. 2014: Ichthyosaurs from the French Rhaetian indicate a severe turnover across the Triassic-Jurassic boundary. Naturwissenschaften 101, 1027-1040.

https://doi.org/10.1007/s00114-014-1242-7.

Fröbisch, N.B., Sander, P.M. \& Rieppel, O. 2006: A new species of Cymbospondylus (Diapsida, Ichthyosauria) from the Middle Triassic of Nevada and a re-evaluation of the skull osteology of the genus. Zoological Journal of the Linnean Society 147, 515-538. https://doi.org/10.1111/j.1096-3642.2006.00225.x.

Fröbisch, N.B., Fröbisch, J., Sander, P.M., Schmitz, L. \& Rieppel, O. 2013: Macropredatory ichthyosaur from the Middle Triassic and the origin of modern trophic networks. Proceedings of the National Academy of Sciences 110, 1393-1397.

https://doi.org/10.1073/pnas.1216750110.

Hansen, B.B., Hammer, Ø. \& Nakrem, H.A. 2018: Stratigraphy and age of the Grippia niveau bone bed, Lower Triassic Vikinghøgda Formation, Spitsbergen. Norwegian Journal of Geology 98, 175-187. https://dx.doi.org/10.17850/njg98-2-02. 
Hounslow, M.W., Peters, C., Mørk, A., Weitschat, W. \& Vigran, J.O. 2008: Biomagnetostratigraphy of the Vikinghøgda Formation, Svalbard (Arctic Norway), and the geomagnetic polarity timescale for the Lower Triassic. Geological Society of America Bulletin 120, 13051325. https://doi.org/10.1130/B26103.1.

Huene, F.R.V. 1916: Beiträge zur Kenntnis der Ichthyosaurier im deutschen Muschelkalk. Palaeontographica 62, 1-68.

Hulke, J.W. 1873: Memorandum on Some Fossil Vertebrate Remains Collected by the Swedisch Expeditions to Spitzbergen in 1864 and 1868. Bihang till Kongliga Svenska Vetenskaps-Akademiens Handlingar 1, 2-11.

Hurum, J.H., Engelschiøn, V.S., Økland, I., Bratvold, J., Ekeheien, C., Roberts, A.J., Delsett, L.L., Bolvig, B., Mørk, A., Nakrem, H.A., Druckenmiller, P.S. \& Hammer, Ø. 2018: The history of exploration and stratigraphy of the early to middle Triassic vertebrate bearing strata of Svalbard (Sassendalen Group, Spitsbergen). Norwegian Journal of Geology 98, 165-174. https://dx.doi.org/10.17850/njg98-2-04.

Ji, C., Jiang, D.Y., Motani, R., Rieppel, O., Hao, W.C. \& Sun, Z.Y. 2015: Phylogeny of the Ichthyopterygia incorporating recent discoveries from South China. Journal of Vertebrate Paleontology 36.

Jiang, D.Y., Motani, R., Hao, W., Schmitz, L., Rieppel, O., Sun, Y. \& Sun, Z. 2008: New primitive ichthyosaurian (Reptilia, Diapsida) from the Middle Triassic of Panxian, Guizhou, southwestern China and its position in the Triassic biotic recovery. Progress in Natural Science 18, 1315-1319. https://doi.org/10.1016/j.pnsc.2008.01.039.

Jiang, D.Y., Motani, R., Huang, J.D., Tintori, A., Hu, Y.C., Rieppel, O., Fraser, N.C., Ji, C., Kelley, N.P., Fu, W.L. \& Zhang, R. 2016: A large aberrant stem ichthyosauriform indicating early rise and demise of ichthyosauromorphs in the wake of the end-Permian extinction. Scientific Reports 6, 1-9. https://doi.org/10.1038/srep26232.

Johnson, R. 1977: Size independent criteria for estimating relative age and the relationships among growth parameters in a group of fossil reptiles (Reptilia: Ichthyosauria). Canadian Journal of Earth Sciences 14, 1916-1924. https://doi.org/10.1139/e77-162.

Kear, B.P. 2004: Biogeographic and biostratigraphic implications of Australian Mesozoic marine reptiles. Australian Biologist 17, 4-22.

Kear, B.P., Fordyce, R.E., Hiller, N. \& Siversson, M. 2017: A palaeobiogeographical synthesis of Australasian Mesozoic marine tetrapods. Alcheringa: An Australasian Journal of Palaeontology, $1-26$.

Kelley, N.P., Motani, R., Embree, P. \& Orchard, M.J. 2016: A new Lower Triassic ichthyopterygian assemblage from Fossil Hill, Nevada. PeerJ 4. https://doi.org/10.7717/peerj.1626.

Kuhn, O. 1934: Ichthyosauria. In Quenstedt, W. (ed.): Fossilium Catalogus. I: Animalia, pars 63, Dr. W. Junk Publishers, Berlin, pp. $1-75$.

Leidy, J. 1868: Notice of Some Reptilian Remains from Nevada. Proceedings of the Academy of Natural Sciences of Philadelphia 20, 177-178.

Lindemann, F.J. 1998: Note on the ichthyosaurian Cymbospondylus. Journal of Paleontology 72, 936-936. https://doi.org/10.1017/S002233600002727X.

Lomax, D.R., De la Salle, P., Massare, J.A. \& Gallois, R. 2018: A giant Late Triassic ichthyosaur from the UK and a reinterpretation of the Aust Cliff 'dinosaurian' bones. PLoS ONE 13. https://doi.org/10.1371/journal.pone.0194742.

Maisch, M.W. 2010: Phylogeny, systematics, and origin of the Ichthyosauria - the state of the art. Palaeodiversity 3, 151-214.

Maisch, M.W. \& Matzke, A.T. 2000: The Ichthyosauria. Stuttgarter Beiträge zur Naturkunde Serie B 298, 1-159.

Maisch, M.W. \& Matzke, A.T. 2002: Observations on Triassic ichthyosaurs. Part IX. The first associated skeletal remains of Merriamosaurus ng (Ichthyosauria, Lower Triassic) and their bearing on the systematic position of the Omphalosauria. Neues Jahrbuch fur Geologie und Palaontologie Abhandlungen 226, 59-94.
Maisch,M.W.\&Matzke,A.T.2003: Observations on Triassicichthyosaurs. Part X: The Lower Triassic Merriamosaurus from Spitzbergen additional data on its anatomy and phylogenetic position. Neues Jahrbuch fur Geologie und Palaontologie Abhandlungen 227, 93-137. https://doi.org/10.1127/njgpa/227/2003/93.

Massare, J.A. \& Callaway, J.M. 1994: Cymbospondylus (Ichthyosauria, Shastasauridae) from the Lower Triassic Thaynes Formation of Southeastern Idaho. Journal of Vertebrate Paleontology 14, 139-141. https://doi.org/10.1080/02724634.1994.10011545.

Maxwell, E.E. \& Kear, B.P. 2013: Triassic ichthyopterygian assemblages of the Svalbard archipelago: a reassessment of taxonomy and distribution. Journal of the Geological Society of Sweden 135, 85-94. https://doi.org/10.1080/11035897.2012.759145.

Mazin, J.M. 1983: Omphalosaurus nisseri (Wiman, 1910), un ichthyoptérygien à denture broyeuse du Trias moyen du Spitsberg. Bulletin du Muséum national d'histoire naturelle. Section C, Sciences de la terre, paléontologie, géologie, minéralogie 5, 243-263.

Mazin, J.M., Suteethorn, V., Buffetaut, E., Jaeger, J.J. \& Elmcke-Ingavat, R. 1991: Preliminary description of Thaisaurus chonglakmanii ng, n. sp., a new ichthyopterygian (Reptilia) from the Early Triassic of Thailand. Comptes rendus de l'Académie des sciences. Série 2, Mécanique, Physique, Chimie, Sciences de lunivers, Sciences de la Terre 313, 1207-1212.

McGowan, C. 1994: A new species of Shastasaurus (Reptilia: Ichthyosauria) from the Triassic of British Columbia: the most complete exemplar of the genus. Journal of Vertebrate Paleontology 14, 168-179. https://doi.org/10.1080/02724634.1994.10011550.

McGowan, C. \& Motani, R. 2003: Part 8: Ichthyopterygia. In Sues, H.D. (ed.): Handbook of Paleoherpetology, Verlag Dr. Friedrich Pfeil, München, pp. 1-182.

Merriam, J.C. 1895: On some reptilian remains from the Triassic of northern California. American Journal of Science 50, 55-57. https://doi.org/10.2475/ajs.s3-50.295.55.

Merriam, J.C. 1902: Triassic ichthyopterygia from California and Nevada. Bulletin of the Department of Geology of the University of California, Publications 3, 63-108.

Merriam, J.C. 1903: New Ichthyosauria from the Upper Triassic of California. Bulletin of the Department of Geology of the University of California, Publications 3, 249-263.

Merriam, J.C. 1905: The types of limb structure in the Triassic Ichthyosauria. American Journal of Science 19, 23-30. https://doi.org/10.2475/ajs.s4-19.109.23.

Merriam, J.C. 1906: Preliminary note on a new marine reptile from the Middle Triassic of Nevada. Bulletin of the Department of Geology of the University of California, Publications 5, 75-79.

Merriam, J.C. 1908: Triassic Ichthyosauria: With Special Reference to the American Forms. Memoirs of the University of California 1, $1-215$.

Merriam, J.C. 1911: Notes on the relationships of the marine saurian fauna described from the triassic of Spitzbergen by Wiman. Bulletin of the Department of Geology of the University of California, Publications 6, 317-327.

Moon, B.C. 2017: A new phylogeny of ichthyosaurs (Reptilia: Diapsida). Journal of Systematic Palaeontology, 1-27. https://doi.org/10.1080/14772019.2017.1394922.

Mørk, A., Elvebakk, G., Forsberg, A.W., Hounslow, M.W., Nakrem, H.A., Vigran, J.O. \& Weitschat, W. 1999: The type section of the Vikinghøgda Formation: a new Lower Triassic unit in central and eastern Svalbard. Polar Research 18, 51-82. https://doi.org/10.3402/polar.v18i1.6558.

Motani, R. 1999: Phylogeny of the Ichthyopterygia. Journal of Vertebrate Paleontology 19, 473-496. https://doi.org/10.1080/02724634.1999.10011160.

Motani, R. 2000: Is Omphalosaurus ichthyopterygian?-A phylogenetic perspective. Journal of Vertebrate Paleontology 20, 295-301. https://doi.org/10.1671/0272-4634(2000)020[0295:IOIAPP]2.0.CO;2. 
Motani, R. \& You, H. 1998: Taxonomy and limb ontogeny of Chaohusaurus geishanensis (Ichthyosauria), with a note on the allometric equation. Journal of Vertebrate Paleontology 18, 533-540. https://doi.org/10.1080/02724634.1998.10011080.

Motani, R., Jiang, D.Y., Chen, G.B., Tintori, A., Rieppel, O., Ji, C. \& Huang, J.D. 2014: A basal ichthyosauriform with a short snout from the Lower Triassic of China. Nature 517, 485-488.

https://doi.org/10.1038/nature13866.

Nicholls, E.L. \& Brinkman, D. 1995: A new ichthyosaur from the Triassic Sulphur Mountain formation of British Columbia. In Sarjeant, W.A.S. (ed.): Vertebrate fossils and the evolution of scientific concepts, Gordon and Breach Publishers, Amsterdam, pp. 521-535.

Nicholls, E.L. \& Manabe, M. 2001: A new genus of ichthyosaur from the Late Triassic Pardonet Formation of British Columbia: bridging the Triassic Jurassic gap. Canadian Journal of Earth Sciences 38, 9831002. https://doi.org/10.1139/e00-115.

Nicholls, E.L. \& Manabe, M. 2004: Giant ichthyosaurs of the Triassic-a new species of Shonisaurus from the Pardonet Formation (Norian: Late Triassic) of British Columbia. Journal of Vertebrate Paleontology $24,838-849$.

https://doi.org/10.1671/0272-4634(2004)024[0838:GIOTTN]2.0.CO;2.

Nordenskiöld, A.E. 1866: Utkast till Spetsbergens geologi. Kongliga Svenska Vetenskaps-Akademiens Handlingar, Stockholm, 35 pp.

Sander, P.M. 1989: The large ichthyosaur Cymbospondylus buchseri, sp. nov., from the Middle Triassic of Monte San Giorgio (Switzerland), with a survey of the genus in Europe. Journal of Vertebrate Paleontology 9, 163-173.

https://doi.org/10.1080/02724634.1989.10011750.

Sander, P.M. 1992: Cymbospondylus (Shastasauridae: Ichthyosauria) from the Middle Triassic of Spitsbergen: filling a paleobiogeographic gap. Journal of Paleontology 66, 332-337. https://doi.org/10.1017/S0022336000033825.

Sander, P.M. 1997: The paleobiogeography of Shastasaurus. In Callaway, J.M. \& Nicholls, E.L. (eds.): Ancient marine reptiles, Academic Press, pp. 17-43. https://doi.org/10.1016/B978-012155210-7/50004-1.

Sander, P.M. 2000: Ichthyosauria: their diversity, distribution, and phylogeny. Paläontologische Zeitschrift 74, 1-35. https://doi.org/10.1007/BF02987949.

Sander, P.M. \& Faber, C. 1998: New finds of Omphalosaurus and a review of Triassic ichthyosaur paleobiogeography. Paläontologische Zeitschrift 72, 149-162. https://doi.org/10.1007/BF02987823.

Sander, P.M. \& Faber, C. 2003: The Triassic marine reptile Omphalosaurus: osteology, jaw anatomy, and evidence for ichthyosaurian affinities. Journal of Vertebrate Paleontology 23, 799816. https://doi.org/10.1671/6.

Scheyer, T.M., Romano, C., Jenks, J. \& Bucher, H. 2014: Early Triassic Marine Biotic Recovery: The Predators' Perspective. PLoS ONE 9. https://doi.org/10.1371/journal.pone.0088987.

Shikama, T., Kamei, T. \& Murata, M. 1978: Early Triassic ichthyosaurus, Utatsusaurus hataii gen. et sp. nov., from the Kitakami Massif, Northeast Japan. The science reports of the Tohoku University, Second series, Geology 48, 77-97.

Weitschat, W. 2008: Intraspecific variation of Svalbardiceras spitzbergensis (Frebold) from the Early Triassic (Spathian) of Spitsbergen. Polar Research 27, 292-297. https://doi.org/10.1111/j.1751-8369.2008.00041.x.

Weitschat, W. \& Dagys, A.S. 1989: Triassic biostratigraphy of Svalbard and a comparison with NE-Siberia. Mitteilungen aus dem Geologisch-Paläontologischen Institut der Universität Hamburg Heft $68,179-213$.

Wiman, C. 1910: AIchthyosaurier aus der Trias Spitzbergens. Bulletin of the Geological Institution of the University of Upsala 10, 124-148.

Wiman, C. 1916: Notes on the marine Triassic reptile fauna of Spitzbergen. Bulletin of the Geological Institution of the University of Upsala 10, 63-73.
Wiman, C. 1928: Eine neue marine Reptilien-Ordnung aus der Trias Spitzbergens. Bulletin of the Geological Institution of the University of Upsala 22, 183-196.

Yakowlew, N.V. 1903: Neue Funde von Trias-Sauriern auf Spitzbergen. Zapiski Imperatoskago S. Peterburgskago mineralogicheskago obshchestva Ser 2., 40, 179-202.

Young, C.C. \& Dong, Z.M. 1972: Chaohusaurus geishanensis from Anhui Province. In Young, C.C. \& Dong, Z.M. (eds.): On the Triassic reptiles of the Triassic in China, Academia Sinica, Institute of Vertebrate Paleontology and Palaeoanthropology, Memoir 9, Peking, pp. 11-14. 